\title{
Determination of a Suitable Renewable Energy Source for Mini-Grid Business: A Risk-Based Multicriteria Approach
}

\author{
Desmond Eseoghene Ighravwe $\mathbb{A D}^{1}$ and Moses Olubayo Babatunde ${ }^{2}$ \\ ${ }^{1}$ Department of Mechanical and Biomedical Engineering, Bells University of Technology, Ota, Nigeria \\ ${ }^{2}$ Department of Electrical and Electronics Engineering, University of Lagos, Lagos, Nigeria \\ Correspondence should be addressed to Desmond Eseoghene Ighravwe; ighravwedesmond@gmail.com
}

Received 28 March 2018; Revised 8 September 2018; Accepted 13 September 2018; Published 14 October 2018

Academic Editor: Nuri Azbar

Copyright (c) 2018 Desmond Eseoghene Ighravwe and Moses Olubayo Babatunde. This is an open access article distributed under the Creative Commons Attribution License, which permits unrestricted use, distribution, and reproduction in any medium, provided the original work is properly cited.

\begin{abstract}
The mini-grid proliferation has helped to improve the current state of electricity supply in several rural areas in developing countries. This is due to the innovations in renewable energy technologies. The impact of this development is the establishment of minigrid business. There is a need for mini-grid business owners to identify the most suitable energy source for a particular area. To achieve this, proper analysis of risks that impact mini-grid business operations is required for optimal energy source selection. The current study addresses this problem by proposing a conceptual framework that considered risk factors. The conceptual framework analysed scenarios where expected risk values are specified and not specified by decision-makers. This was achieved using fuzzy axiomatic design (FAD), intuitionistic entropy method, and TOPSIS (Technique for Order Performance by Similarity to Ideal Solution) methods. The TOPSIS and FAD results were combined using WASPAS (weighted aggregated sum product assessment) method. The proposed conceptual framework was applied in sub-Sahara Africa, Lagos, Nigeria. During the application of the proposed framework, five renewable energy sources and thirteen types of risks were considered. Information from four decisionmakers was used to demonstrate the applicability of the framework. The results obtained showed that unpredictable electricity demand and construction completion risks were identified as the least and most important risks for the selection of renewable energy sources for mini-grid, respectively. The FAD and TOPSIS methods identified wind and biomass energy as the best-ranked energy source for mini-grid business, respectively. The WASPAS method and the FAD results were the same.
\end{abstract}

\section{Introduction}

Energy business in developing countries is a lucrative business. This is due to the inability of government in these countries to meet energy demand. This government's inability is due to their dependence on conventional power plants. Most of the power plant performance is affected by environmental conditions and technological factors. For example, variation in water volume affects the capacity of a hydrothermal plant. Poor maintenance culture of the existing fossil fuelpowered power plants reduced the capacity of these plants. This has created a huge gap between energy production and demand, thus, creating a market for private investors in minigrid business. These investors provide alternative sources of energy for urban and rural settlements.

Investors in the energy market usually adopt different mode of operations. These investors specialize in macro-grid, mini-grid, and nano-grid energy businesses, which are either off-grid mode or grid-connected. Several attempts have been made to distinguish these grids from one another; however, consensus on their size boundaries has not been reached [1] Despite this issue, mini-grid, whose capacity ranges between $10 \mathrm{KW}$ and 10MW, has been identified as being suitable for locations where there is a national grid [2]. This attribute of mini-grid is among one of the reasons why mini-grid common in most developing countries. Others are its ability to align and to be adapted for the base of the pyramid market characteristics [2]. Investors have used different types of mini-grid business models to meet energy demand. Private, community-based, and utility business models have proven to be useful business models. In some areas, hybrid minigrid business has been adopted to further improve energy supply. For example, a public-private business model has 
been encouraged by governments in Africa. This has helped to reduce the risks associated with operating a mini-grid business in developing countries.

There are several risks that are associated with minigrid business in developing countries. Operational risk is the predominant risk in operating a mini-grid business. It can arise from business and customers miscommunication, unavailability of skilled technicians, and fraud. Mini-grid businesses also suffer from a natural disaster such as volcanic eruptions, storm, and mudslides. This type of risk is known as force majeure risk. This type of risk is closely related to environmental risk such as cloud coverage, hail, and low rainfall. These risks are further enhanced by the issue of vandalism and theft of mini-grid components such as fuel, photovoltaic panels, and copper wires. The risk of fixing a damaged mini-grid on time affects the profit margin of a mini-grid business, especially in developing countries. The inability to complete a mini-grid project may be due to spare parts unavailability, engineering challenges, and structural problems. This affects the level of technology that is employed in a mini-grid business. If a very high technology is deployed in a mini-grid, there is a high possibility of experiencing a technological risk.

The lack of reliable data on electricity consumption makes it difficult for business owners to predict electricity demand. This problem introduces a demand risk into minigrid business. In some cases, the inability of customers to pay for an electric bill is a challenge. This is often experienced where there is inconsistency in electricity regulations. There needs to be in place good policies that will help to curb this type of risk. Mini-grid which uses a feedstock as a raw material may suffer from raw-material unavailability risk as well as the acceptable risk from the host community. Some member of a community believes that such mini-grid will put more pressure on scarce resources. This is a common problem with biogas and biodiesel energy production.

This problem is minimal when considering the other mini-grid energy sources such as wind, solar, and hybrid sources. However, other types of risks affect these energy sources. This implies that proper analysis of risks is required when selecting a renewable energy source for a mini-grid business. This creates a multicriteria problem. This is a complex problem because it is difficult to evaluate and quantify some of the risks that affect mini-grid business. This implies that the qualitative values of risk must be considered during the evaluation process. The proposed conceptual framework adequately caters for this problem using fuzzy logic concept (i.e., intuitionistic fuzzy numbers). The conceptual framework considered conditions where risk values are specified and not specified by decision-makers. A FAD is used to address the condition where risk values are specified by decision-makers. This is because of its ability in using the design requirements in selecting the best alternative to a problem. TOPSIS is used for the condition where risk values are not specified by decision-makers.

The aim of this study is to determine the most suitable renewable energy source for mini-grid business in a developing country under risk considerations. This is achieved by combining intuitionistic entropy method (IEM) results in a FAD and TOPSIS framework. While FAD method is considered because of its ability to combine design and system requirements during a decision-making process, IEM is selected because of its capacity to improve results precision by virtue of the inclusion of intuitionistic fuzzy number in its structure (Wu and Cao, 2013). On the part of TOPSIS, its selection is based on its ability to combine the best and worst results in ranking alternatives. The results from FAD and TOPSIS methods are combined using WASPAS (weighted aggregated sum product assessment) method; these methods results were considered as criteria during the implementation of the WASPAS method. This enabled us to further rank the mini-grid business models.

\section{Literature Review}

This study's literature review is in two phases. In the first phase, articles on multicriteria models in energy study were reviewed, while mini-grid business models were reviewed in the second phase.

2.1. Multicriteria Models in Energy Study. Optimal energy design and planning analysis encompasses selecting a set of resources, conversion strategies, and sites so as to meet a specific energy demand. This is often considered during a system's energy planning and appraisal phases. By virtue of this, a balance can be maintained among various factors, such as environmental, socio-political, technical, and economic aspects, over a planning horizon. This balance is vital to the sustainability of the environment as well as the project itself. Technical-economic and environmental factors are typically presented in the form of multiple criteria and indices with conflicting objectives. This is necessary because of the interactions among the different factors. It is difficult to determine the boundary between the diverse factors and indicators. Hence, the strength of multicriteria multiattribute (MCDA) methods is suitable for undertaking assessment procedures. Several authors have contributed to the discussions on MCDA for energy study under renewable and nonrenewable energy analysis.

Tolga and Kahraman (2010) presented a twofold study on multicriteria renewable energy planning for Istanbul. They used a hybrid VIKOR-AHP methodology to select the best renewable energy option for Istanbul. It further identified the optimal location for the energy alternatives using the same methodology. The results established that the wind energy production alternative is the best for the region under consideration. Catalca region was also identified as the optimal location for the siting of the wind plant. Most times, expert judgments on energy planning decisions are usually subjected to uncertainty. In order to address this, Tolga and Kahraman (2010) applied a modified fuzzy TOPSIS method for evaluating and selecting optimal energy technology. A fuzzy set theory was used to address the uncertainty of the information from experts. They also performed a sensitivity analysis by varying the criteria weights to generate four additional case studies. Biomass was ranked two times as the best alternative, while the wind technology was ranked optimally two times. In line with the renewable energy 
planning (REP) of the Spanish government, San Cristóbal [3] examined the selection of renewable energy project using a combined VIKOR and AHP method. Seven attributes were identified for selecting the best alternative. Out of the 13 power generation alternatives, biomass plant (co-combustion in conventional central) was identified as the best energy generation alternative. This was followed by the wind energy whose capacity ranges between 10 and 50MW and solar thermoelectric alternatives, respectively.

In a review of energy planning literature between early 1990 and 2002, presented by Pohekar and Ramachandran [4], it was observed that AHP (20\%) ranks as the most used tools. This was followed by ELECTRE (15\%) and PROMETHEE (10\%), respectively. Other methods such as decision support system (DSS) and fuzzy accounted for $20 \%$ of the decisionmaking methods. However, the multiobjective optimization techniques had the highest share of $29 \%$. Georgopoulou et al. [5] applied the ELECTRE III methodology to select the best renewable energy alternative and strategy for Crete Island. Kahraman and Kaya [6] proposed the use of a fuzzy multicriteria decision-making approach for the selection of the best energy policy. Their method was based on a fuzzy-AHP framework. Their analysis considered hard coal and lignite oil, natural gas, hydropower, geothermal, wind, solar, nuclear, and wood and waste. The most viable energy investment policy was wind energy. The efficacy of applying PROMETHEE II in the outranking geothermal resource exploitation was presented by Haralambopoulos and Polatidis [7]. They used an integrated dynamic framework based on PROMETHEE II to rank renewable energy project action plan in the island of Chios. Martín-Gamboa [8] explored the potentials of adopting the life cycle, data envelopment analysis within the sustainability-oriented MCDA in the field of energy. Kumar et al. [9] presented a comprehensive review of various essential topographies of the MCDA, algorithms available with respect to the planning and selection of renewable energy sources schemes.

Recently, Wang et al. [10] presented a review of various techniques in different stages of multicriteria decisionmaking process in the field of sustainable energy. These include the selection of criteria, weighting, evaluation, and aggregation. Sengül et al. [11] developed a decision framework for ranking renewable energy alternatives using the fuzzyTOPSIS technique. To determine the weight of the criteria, interval Shannon's entropy method was adopted. They implemented their model using Turkey as a case study. Hydropower station was identified as the most suitable renewable energy. Alsayed et al. [12] presented an optimal sizing MCDA based technique for an embedded generation. Kahraman et al [13] presented a comparative study on the use of fuzzy-AHP and fuzzy-axiomatic design $(\mathrm{AD})$ in the selection of renewable energy technology in Turkey. Wind energy was identified as the most promising renewable energy alternative. Polatidis and Haralambopoulos [14] presented a regulatory and contextual framework for participatory MCDA for energy planning using Greece as a case study.

Streimikiene et al. [15] analysed the best long-term electricity generation approach in Lithuania using AHP and Additive Ratio Assessment (ARAS) method. The assessment shows that the optimal electricity generation option for the Lithuania power sector is the construction of a new nuclear power plant, followed by a biomass and hydropower plant, respectively. Mardani et al. [16] carried out a comprehensive review study on MCDM approaches applied in various areas of energy management published between 1995 and 2015. Fifty-five papers out of the reviewed studies integrated hybrid MCDA and fuzzy MCDA with respect to energy management and 49 papers used fuzzy AHP and classical AHP, while 25 papers applied MCDA and MCA techniques. Malkawi et al. [17] accessed and classified the electricity generation alternatives for Jordan using AHP. The ranking of the alternatives was based on economic, technical, environmental, social, and risk assessment. The electricity generation options considered consist of both conventional and renewable sources. Based on economic and technical conditions, the results revealed that the use of a conventional source of generation was discovered to be the most viable alternative. Tsoutsos et al. [18] presented a multicriteria algorithm for energy sustainability planning in Crete Island, Greece, They considered a set of energy planning options. PROMETHEE method was applied for the planning scheme. Mardani et al. [19] proposed and implemented a hierarchical framework for appraising and classifying the important energy-saving alternatives in 10 Iranian hotels using hybrid fuzzy set theory. Onut et al. [20] examined the energy resource use in the Turkish manufacturing industry using benefits, cost, and opportunities as well as risks as key attributes. They used ANP to evaluate and select the appropriate energy resource.

2.2. A Review of Mini-Grid Business Model. Although no formal definition of mini-grid business model has been universally adopted, the classification and definition are usually based on ownership and institutional arrangement [21]. World Bank defines and classifies mini-grid according to the ownership (private, nongovernmental, and public) as well as the type of technology (grid extension, off-grid) (ESMAP 2006). According to Krithika and Palit [21], each of these institutional models has its peculiar feature with regard to rights, financing instruments, services, and internal processes. The UNDP classified mini-grid into four basic delivery business models [22]. A brief description of the classifications is given in Table 1 .

Access to affordable and reliable energy system is a major challenge in rural communities [23]. The residents of these communities majorly engage in agricultural related activities with low-income level. Furthermore, the income is often periodic and inconsistent throughout the year. Since majority of the population is involved in agricultural activities, the affordability of putting up an electrification project and its associated costs (operational and maintenance costs, repair and replacement costs, etc.) is not realistic [24-27].

The affordability factor is a major bottleneck to increasing energy penetration as evident in Nepal, Indonesia, and Zambia, to mention a few [28-30]. Many rural consumers of electricity may prefer the use of kerosene for lighting because the electricity tariff for lighting load is just as cheap as using kerosene. In Indonesia, to get access to electricity, 
TABle 1: Mini-grid business model classification.

\begin{tabular}{ll}
\hline Model & Descriptions \\
\hline \multirow{3}{*}{ Public utility } & (i) Mini-grid is owned and managed by a utility. \\
& (ii) Uniform national tariff is applicable. \\
& (iii) Investment is through public funds. \\
\hline & (i) Community or local NGO owns and manages all aspects of the mini-grid. \\
(ii) It is financed by grants and small in-kind contributions such as land, labour and materials. \\
(iii) Tariffs cover only operation and maintenance costs, and a small percentage is retained for \\
parts replacements. \\
(iv) Operated by a local group with little contributions from professionals. \\
\hline (i) Built, owned and operated by private companies. \\
(ii) Financing is obtained through equity, commercial or concessional loans, and grants. \\
(iii) Tariffs are usually higher in the absence of government subsidies. \\
(iv) Models are steered by suppliers and dealers who participate in reinforcing and building an \\
electricity market that responds to consumers purchasing capacity. \\
(i) Integrates the features of other business models. \\
(ii) Ownership of different parts of the model is diversified. \\
(iii) Effectiveness and efficiency are higher than other models. \\
(iv) Private sector installs the equipment free of charge, operates and maintains the system under \\
a concession and recoups its investment through collecting tariffs from end users.
\end{tabular}

consumers must make an initial down payment followed by a regular monthly payment. The ownership of the system is only transferred to the consumers after the complete payment for the system is made. However, to acquire this project, it is found that consumers only have access to a loan which is characterized by high down payments and short repayment period. This has greatly limited the penetration of electricity in rural communities [28]. In Zambia, the Energy Service Company (ESCOs) installed solar PV system for 400 energy consumers. The project, however, failed due to the high monthly payment fee. Most consumers (especially entrepreneurs and farmers) withdrew because the payment scheme could only be maintained by civil servants with regular monthly income $[29,30]$.

Many mini-grids in developing economies are faced with technical challenges. Consequently, this has affected access to reliable electricity negatively. According to Khennas and Barnett [31], a survey conducted on micro-hydro project in Nepal revealed that, despite adequate manuals, procedures, training, and standards available, approximately 30 percent of the installation failed during operation due to poor site selection, poor installation, abandonment of civil structures, etc. Similarly, biomass gasifier technology received limited a level of penetration in India due to lack of technical standards and specifications that can enhance quality product Palit and Chaurey [32].

The applicability of mini-grid technologies in alleviating energy poverty for rural electrification is another area where little has been achieved (Zerriffi, 2007). Hence, the inability of operators to replicate the successes in other viable minigrid projects is a source of concern for decision-makers. It has been discovered that it is difficult to replicate many of the mini-grid technologies that have worked on a commercial scale due to the absence of adequate policies, viable maintenance structure, and sustainable operation as well as financing (Martinot et al., 2002). For example, over 35,000 biogas plants were constructed in Nepal between 1992 and 1998. The technology was largely embraced by small and lower-income farmers due to the implementation of subsidies and affordable financing schemes (Martinot et al., 2002). It was reported that a joint sustainability effort on the part of the owners and installers as well as programme staff was the brain behind the excellent performance of the scheme. The scheme also made sure the users received financial incentives $[33,34]$. On the contrary, the replicability of a biogas plant in sub-Saharan Africa experienced different challenges. These include inadequate feedstock, intensive labour demand, high capital costs, poor technical performance, and lack of water $[35,36]$.

Hence, the major problem impeding the adoption of mini-grids can be categorised under the following: (i) deficiency in policy and regulatory standards in relation to tariffs, licensing, and evacuation of power (ii) lack of sustainable business models; (iii) lack of access to adequate funding; (iv) stakeholders' lack of expertise.

For now, our focus is on the issue of business model selection. This issue is considered so as to further hence the long-term economic and social benefits of operating a mini-grid business. However, there is sparse information on how to rightly select this model. For instance, there is no information on how to use design or system requirements to make this decision. Even if these requirements are ignored, decision-makers are constrained with lack of information on how to combine different requirements into a single index that will aid such selection process. Another limitation is that literature on this business model rarely considered the use of linguistic values to support their decisions on mini-grid business model selection.

In an attempt to fill these knowledge gaps, a framework that used inputs from decision-makers is presented. One of the attributes of the framework is that it uses a FAD to handle a situation where design requirements for 


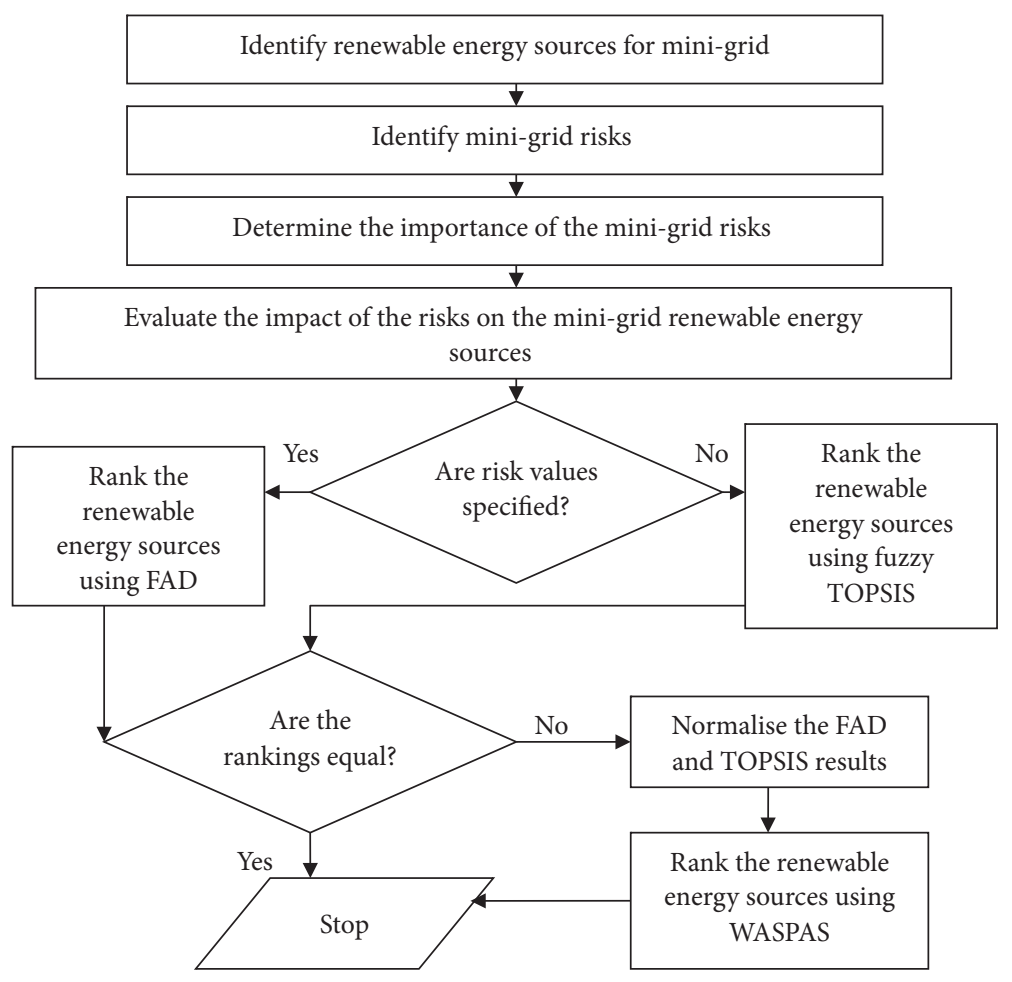

FIGURE 1: Proposed framework for mini-grid energy source selection.

a business model are specified, while a TOPSIS method is used to handle a situation when design requirements are not specified. Using a WASPAS method, the framework takes these situations further by converging the former and latter situation results. This effort is a preemptive move that handles discrepancy between a FAD and TOPSIS best-ranked business model.

\section{Methodology}

The proposed methodology for the renewable energy selection problem is based on the combination of a FAD, TOPSIS, WASPAS, IEM, and intuitionistic fuzzy numbers. Some of the justifications for selecting these methods are as follows.

(i) TOPSIS method has several advantages over other MCDM tools $[37,38]$. In terms of rank reversal, it has the fewest characteristics and it is easy to implement using a spreadsheet [37, 38]. Also, comparison of alternatives is done directly based on the values of evaluation factors and their weights. This makes it possible for the method to consider the best and worst values in a decision matrix [37, 38]. Other interesting attributes of this method are contained in the works of Zanakis et al. [37].

(ii) While FAD has the unique attribute of using design and system requirements to rank alternatives, WASPAS method ranked alternatives based on their weighted sum and product values [39]. It uses aggregated coefficient to combine these values. Another WASPAS attribute distinguished from other MCDM is that it can be used to simulate different ranks for alternatives. To achieve this, WASPAS varies the aggregation coefficient for different scenarios.

These tools are methodologically connected so as to improve mini-grid energy source selection in developing countries (Figure 1).

3.1. Mini-Grid Risks. The above-mentioned risks are used to determine the most suitable energy source for mini-grid in developing countries. Solar $\left(\mathrm{S}_{1}\right)$, biodiesel $\left(\mathrm{S}_{2}\right)$, biomass $\left(\mathrm{S}_{3}\right)$, wind $\left(\mathrm{S}_{4}\right)$, and hybrid $\left(\mathrm{S}_{5}\right)$ energy sources are considered as a potential energy source for a mini-grid.

3.2. Intuitionistic Entropy Method. Entropy method has helped to reduce the complex mathematical analysis that is required for criteria importance determination. It has helped to reduce the complex mathematical analysis that is required for criteria importance determination. Its scope has extended to the use of linguistic terms. This was made possible by incorporating fuzzy logic into its framework. One of such framework is intuitionistic entropy method. This type of entropy method consists of membership and nonmembership functions in a universe of discourse (see (1)). This expression is subject to (2).

$$
\begin{aligned}
& A=\left\{\left\langle x, \mu_{A}(x), v_{A}(x) \mid x \in X\right\rangle\right\} \\
& 0 \leq \mu_{A}(x)+v_{A}(x) \leq 1
\end{aligned}
$$

where $\mu_{A}(x)$ and $v_{A}(x)$ represent membership and nonmembership functions, respectively. 
Based on (2), the intuitionistic index of $x$ in $A$ is given as (3).

$$
\begin{aligned}
\pi_{A}(x) & =1-\mu_{A}(x)-v_{A}(x) \\
0 & \leq \pi_{A}(x) \leq 1
\end{aligned}
$$

Hung and Chen [40] reported that, to generate the aggregated value for two or more decision-makers using IFSs, (5) is used to compute a criterion crisp value during entropy method application.

$$
\begin{aligned}
& E_{L T}^{I F S}\left(C_{j}\right)=\frac{1}{2} \sum_{i=1}^{m}\left[\mu_{i j}\left(C_{j}\right) \operatorname{lm} \mu_{i j}\left(C_{j}\right) \operatorname{lm} v_{i j}\right. \\
& \left.\quad-\left(1-\pi_{i j}\left(C_{j}\right)\right) \operatorname{lm}\left(1-\pi_{i j}\left(C_{j}\right)\right)-\pi_{i j}\left(C_{j}\right) \operatorname{lm} 2\right] \\
& d_{j}=1-E_{L T}^{I F S}\left(C_{j}\right) \\
& w_{j}=\frac{d_{j}}{\sum_{j=1}^{n} d_{j}}
\end{aligned}
$$

where $w_{j}$ represents the criterion $j$ importance.

3.3. FAD. A FAD is a robust multicriteria selection tool that has the capacity to use design requirements in selecting the best alternative for a problem. Its acceptance is further strengthened by its capacity to analyse linguistic information. The linguistic terms are converted into crisp values using fuzzy numbers [41, 42]. Triangular and trapezoidal are among the frequently used fuzzy numbers for this conversion operation. Since FAD can be implemented using two or more decision-makers, mathematical operations are used to aggregate decision-makers responses. For example, the aggregation of a trapezoidal fuzzy number is given by (8) to (11).

$$
\begin{aligned}
& x_{i j}^{1}=\min _{k}\left(x_{i j k}^{1}\right) \\
& x_{i j}^{2}=\frac{1}{K} \sum_{k=1}^{K} x_{i j k}^{2} \\
& x_{i j}^{3}=\frac{1}{K} \sum_{k=1}^{K} x_{i j k}^{3} \\
& x_{i j}^{4}=\max _{k}\left(x_{i j k}^{4}\right)
\end{aligned}
$$

where $x_{i j}^{1}, x_{i j}^{2}, x_{i j}^{3}$, and $x_{i j}^{4}$ denote the first, second, third, and fourth vertex values of a trapezoidal fuzzy number, respectively, for alternative $i$ with respect to criterion $j$.

The selection of the best-ranked alternative to a problem is based on the concept of information content [42]. The value of information content is a function of the system area and the common area between the system and design requirements [42]. The information content for a criterion is expressed as (12), while (13) gives the total weighted information contents of an alternative. The decision on the

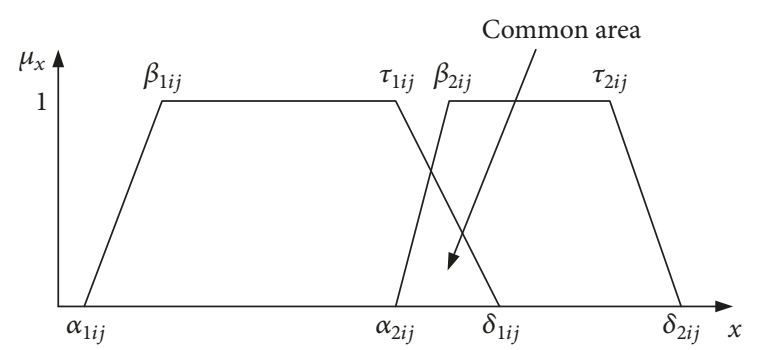

FIGURE 2: Trapezoidal fuzzy numbers for system and design requirements.

best-ranked alternative is based on the alternative with the highest weighted information content value [41, 42].

$$
\begin{gathered}
I_{i j}=\log _{2} \frac{S_{i j}}{C_{i j}} \\
I_{i}=\sum_{j=1}^{n} W_{j} I_{i j}
\end{gathered}
$$

where $C_{i j}, S_{i j}$, and $I_{i j}$ represent the common areas, system area, and information content of alternative $i$ for criterion $j$, $W_{j}$ represents the importance of criterion $j$, and $I_{i}$ represents the total weighted information content for alternative $i$ [42].

Khandekar and Chakraborty [41] reported that the common area for trapezoidal fuzzy numbers is given as (14). The system area is the area of the trapezoidal fuzzy number (see (15)). The interaction between a system and design requirements using a trapezoidal fuzzy number is shown in Figure 2.

$$
\begin{aligned}
& C_{i j}=\frac{\left(\delta_{1 i j}-\alpha_{2 i j}\right)^{2}}{2\left(\delta_{1 i j}-\beta_{1 i j}+\beta_{2 i j}-\alpha_{2 i j}\right)} \\
& S_{i j}=\frac{1}{2}\left[\left(\delta_{1 i j}-\alpha_{1 i j}\right)+\left(\tau_{1 i j}-\beta_{1 i j}\right)\right]
\end{aligned}
$$

3.4. TOPSIS. Practical problems are typically characterized by various conflicting attributes and there may be no single solution that satisfies these attributes. In such cases, the multicriteria decision approach (MCDA) is usually adopted. In MCDA, it is of priority to evaluate and compare various alternatives using a number of criteria. Hence, the MCDA helps decision-makers to make a choice among alternatives with conflicting attributes. One of such MCDA tools is the TOPSIS. The TOPSIS method was originally proposed by Yoon and Hwang [43] as well as Lai et al. [44]. The TOPSIS framework is based on the fact that the selected alternative should have the shortest Euclidian distance from the positive ideal solution and the farthest from the negative ideal solution [45-48].

Therefore, it has the tendency to consider both the best and worst case scenarios among the set of alternatives. Another advantage of this method is its simplicity in the presentation of linguistic terms. The ability of a TOPSIS method to incorporate fuzzy logic (i.e., fuzzy TOPSIS) makes it versatile for many multicriteria problems. It, therefore, 
makes this tool appropriate for selecting renewable energy mini-grid under various risks. The steps involved in the implementation of TOPSIS are as follows [46-48]:

Step 1 (establishment of decision matrix and determination of the weight criteria). Let $X=\left(x_{i j}\right)$ be a decision matrix and $W=\left(w_{1}+w_{2}+, \ldots, w_{n}\right)$ a weight vector, where $x_{i j} \in \mathfrak{R}, w_{j} \in$ $\Re$ and $w_{1}+w_{2}+, \ldots, w_{n}=1$.

Step 2 (calculate the normalised decision matrix). The normalisation of values can be carried out by one of the several known standardized formulas. Some of the most frequently used methods of calculating the normalised values when dealing with standard TOPSIS methods are as follows:

$$
\begin{aligned}
& \bar{x}_{i j}=\frac{x_{i j}}{\sqrt{\sum_{j=1}^{n} x_{i j}^{2}}} \\
& \bar{x}_{i j} \\
& = \begin{cases}\frac{x_{i j}-\min _{i} x_{i j}}{\max _{i} x_{i j}-\min _{i} x_{i j}} & \text { if } x_{i j} \text { is benefit criterion } \\
\frac{\max _{i} x_{i j}-x_{i j}}{\max _{i} x_{i j}-\min _{i} x_{i j}} & \text { if } x_{i j} \text { is non-benefit criterion }\end{cases}
\end{aligned}
$$

where $x_{i j}$ and $\bar{x}_{i j}$ denote the original and normalised values of alternative $i$ with respect to criterion $j$, respectively.

Equations (16) and (17) cannot be used in fuzzy TOPSIS application. Normalisation in fuzzy TOPSIS application is based on the type of fuzzy numbers that are considered in converting linguistic terms to crisp values. For trapezoidal fuzzy numbers, normalisation is carried out with (18).

$$
\begin{aligned}
& \bar{\alpha}_{i j}, \bar{\beta}_{i j}, \bar{\tau}_{i j}, \bar{\delta}_{i j} \\
& =\left\{\begin{array}{l}
\frac{\alpha_{i j}}{\delta_{j}}, \frac{\beta_{i j}}{\delta_{j}}, \frac{\tau_{i j}}{\delta_{j}}, \frac{\delta_{i j}}{\delta_{j}} \quad \text { if } x_{i j} \text { is benefit criterion } \\
\frac{\alpha_{j}}{\delta_{i j}}, \frac{\alpha_{j}}{\tau_{i j}}, \frac{\alpha_{j}}{\beta_{i j}}, \frac{\alpha_{j}}{\alpha_{i j}} \text { if } x_{i j} \text { is non-benefit criterion }
\end{array}\right. \\
& \delta_{j}=\max _{i} \delta_{j} \\
& \alpha_{j}=\min _{i} \alpha_{j}
\end{aligned}
$$

where $\bar{\alpha}_{i j}, \bar{\beta}_{i j}, \bar{\tau}_{i j}$, and $\bar{\delta}_{i j}$ denote the normalised values of the first, second, third, and fourth vertex of a trapezoidal fuzzy number, respectively, for alternative $i$ with respect to criterion $j$.

Step 3 (calculate the weighted normalised decision matrix). The weighted normalised value of normalised fuzzy numbers is obtained by multiplying the normalised values with the criteria weights (see (21)).

$$
\widetilde{\alpha}_{i j}, \widetilde{\beta}_{i j}, \widetilde{\tau}_{1 i j}, \widetilde{\delta}_{i j}=w_{j}\left(\bar{\alpha}_{i j}, \bar{\beta}_{i j}, \bar{\tau}_{i j}, \bar{\delta}_{i j}\right)
$$

where $w_{j}$ denotes the weight for criterion $j$ and $\widetilde{\alpha}_{1 i j}, \widetilde{\beta}_{1 i j}$, $\widetilde{\tau}_{1 i j}$, and $\widetilde{\delta}_{1 i j}$ denote the weighted normalised values of the first, second, third, and fourth vertex values of a trapezoidal fuzzy number, respectively, for alternative $i$ with respect to criterion j.
Step 4 (determine the positive ideal and not-ideal solutions). The distance of each alternative from the ideal and negative ideal solutions is based on the selection of the ideal and notideal solutions. This is done with the same type of fuzzy number for the evaluation process. Equations (22) and (23) are commonly used as the ideal and not-ideal solutions. The distances of the criteria from the ideal and not-ideal solutions are given by (23) and (25), respectively.

$$
\begin{aligned}
I^{+}= & (1,1,1,1) \\
I^{-}= & (0,0,0,0) \\
d_{i j}^{+}= & \left(\alpha_{1 i j}-I_{1}^{+}\right)^{2}+\left(\beta_{2 i j}-I_{2}^{+}\right)^{2}+\left(\tau_{1 i j}-I_{3}^{+}\right)^{2} \\
& +\left(\delta_{1 i j}-I_{4}^{+}\right)^{2} \\
d_{i j}^{-}= & \left(\alpha_{1 i j}-I_{1}^{-}\right)^{2}+\left(\beta_{2 i j}-I_{2}^{-}\right)^{2}+\left(\tau_{1 i j}-I_{3}^{-}\right)^{2} \\
& +\left(\delta_{1 i j}-I_{4}^{-}\right)^{2}
\end{aligned}
$$

where $d_{i j}^{+}$and $d_{i j}^{-}$denote the distance of alternative $i$ with respect to criterion $j$ from the ideal $\left(I^{+}\right)$and not-ideal $\left(I^{-}\right)$ values of criterion $j$.

The ideal solution distance of the alternatives is expressed as (26), while (27) gives the not-ideal solution distance of the alternatives.

$$
\begin{aligned}
& D_{i}^{+}=\sqrt{\sum_{i=1}^{n} d_{i j}^{+}} \\
& D_{i}^{-}=\sqrt{\sum_{i=1}^{n} d_{i j}^{-}}
\end{aligned}
$$

where $D_{i}^{+}$and $D_{i}^{-}$denote the ideal and not-ideal solutions of alternative $i$, respectively.

Step 5 (calculate the relative closeness to the ideal solution). The relative closeness of the alternatives is expressed as (28). The best-ranked alternative is the alternative with the highest relative closeness [42].

$$
\begin{aligned}
D_{i} & =\frac{D_{i}^{-}}{D_{i}^{+}+D_{i}^{-}} \\
0 & \leq D_{i} \leq 1
\end{aligned}
$$

3.5. WASPAS Method. The WASPAS method combines two MCDA weighted sum and weighted product models. The first step requires the generation of an evaluation matrix $X=\left[x_{i j}\right]_{m n} . x_{i j}$ represents the performance of $i^{\text {th }}$ alternative with respect to $j^{\text {th }}$ criterion, $m$ represents the number of alternatives, and $n$ represents the number of criteria. For the current study, the outputs from the FAD and fuzzy TOPSIS methods are considered as criteria. However, there is the possibility of the FAD generating a negative value. This 
problem is addressed by adding a constant value to the final outputs of the FAD method (see (30)).

$$
R I_{i}=\Delta+I_{i}
$$

where $R I_{i}$ and $\Delta$ represent the regularised information content for alternative $i$ and constant value, respectively.

The next step is the normalisation of the criteria values. This is done using (16). This is followed by computing the weighted sum and weighted product values for the alternatives ((31) and (32)). The combination of the results from (31) and (32) gives the WASPAS outputs of the alternatives (see (30)). This is achieved by using a controlling parameter whose value ranges between 0 and $1(\lambda)$. The most suitable alternative to a problem is the alternative with the highest index (see (33)).

$$
\begin{aligned}
Q_{i}^{+} & =\sum_{j=1}^{n} \bar{x}_{i j} w_{j} \\
Q_{i}^{-} & =\prod_{j=1}^{n} \bar{x}_{i j} w_{j} \\
Q_{i} & =\lambda Q_{i}^{+}+(1+\lambda) Q_{i}^{-}
\end{aligned}
$$

where $Q_{i}^{+}, Q_{i}^{-}$, and $Q_{i}^{-}$denote the weighted sum, weight product, and weighted aggregated sum product assessment for alternative $i$, respectively, and $\lambda$ denotes a contribution parameter.

\section{Case Study}

The frameworks were applied in Lagos, southern Nigeria. Nigeria is a developing country located in Sub-Sahara Africa and endowed with substantial renewable energy resource which comprises solar energy, wind energy, small hydroelectric energy potentials, biomass, untapped hydrogen exploitation, and development of geothermal and ocean energy technologies. The country has the tendency to generate approximately $3.5 \mathrm{kWh} / \mathrm{m}^{2} /$ day in the coastal areas to almost $7.0 \mathrm{kWh} / \mathrm{m}^{2} /$ day in the north. Wind speeds in Nigeria range between 1.4 and $3.0 \mathrm{~m} / \mathrm{s}$ in the south and 4.0 and $5.12 \mathrm{~m} / \mathrm{s}$ in the far north [23]. Biomass resources available in Nigeria include forage grasses, wood, shrubs, animal and human waste, and other wastes from agriculture as well as aquatic biomass (Nnamdi et al 2011). In 2007 biodiesel policy gave rise to the $10 \%$ ethanol inclusion into petroleum products in the country [49]. Current estimates show that about 61 million tonnes/year of animal waste can be accomplished and that about 83 million tonnes/year of crop residue can be produced. The organic waste alone has the potential to yield about 169541.66 MWh of electricity on an annual basis. Solar energy generation in Lagos is currently being explored for commercial purpose. Being a coastal area, the potentials of wind-generated energy are also promising. Based on the energy resources available in Lagos, Nigeria, micro-grid power generation can be accomplished using solar, biomass, wind, biodiesel, or a hybrid of these resources. However, due to the abundance of solar and organic waste in Lagos
TABLE 2: Risks for the evaluation of mini-grid energy sources.

\begin{tabular}{lc}
\hline Risks & Symbols \\
\hline Operational risk & $\mathrm{C}_{1}$ \\
Theft and vandalism risk & $\mathrm{C}_{2}$ \\
Foreign exchange risk & $\mathrm{C}_{3}$ \\
Force majeure risk & $\mathrm{C}_{4}$ \\
Environmental risk & $\mathrm{C}_{5}$ \\
Social acceptance risk & $\mathrm{C}_{6}$ \\
Unpredictable electricity demand risk & $\mathrm{C}_{7}$ \\
Construction completion risk & $\mathrm{C}_{8}$ \\
Resource availability risk & $\mathrm{C}_{9}$ \\
Technology risk & $\mathrm{C}_{10}$ \\
Resource price variability risk & $\mathrm{C}_{11}$ \\
Non-payment of electricity bills risk & $\mathrm{C}_{12}$ \\
Political and legal (regulatory) risk & $\mathrm{C}_{13}$ \\
\hline
\end{tabular}

TABLE 3: Linguistic terms for the effects of risks on the different energy sources.

\begin{tabular}{lc}
\hline Linguistic terms & Fuzzy numbers \\
\hline Very low (VL) & $(0.05,0.10,0.20,0.30)$ \\
Low $(\mathrm{L})$ & $(0.10,0.30,0.40,0.55)$ \\
Moderate $(\mathrm{M})$ & $(0.25,0.45,0.55,0.65)$ \\
High $(\mathrm{H})$ & $(0.50,0.55,0.60,0.65)$ \\
Very high $(\mathrm{VH})$ & $(0.65,0.75,0.80,9.00)$ \\
Extremely high $(\mathrm{E})$ & $(0.80,0.90,0.10,1.00)$ \\
\hline
\end{tabular}

$(1,104,001.92$ tonnes/annum, the highest in Nigeria) a hybrid of solar and biodiesel is considered as a hybrid alternative in this study [50].

During the application of the proposed framework, five different energy sources were considered. These energy sources are solar energy $\left(\mathrm{S}_{1}\right)$, biodiesel $\left(\mathrm{S}_{2}\right)$, biomass energy $\left(S_{3}\right)$, wind energy $\left(S_{4}\right)$, and hybrid energy (solar-biodiesel) $\left(\mathrm{S}_{5}\right)$. Thirteen different types of risks were considered (Table 2). Four decision-makers were asked to evaluate the different risks involved in using these energy sources for mini-grid business. Three of the experts are academic with vast professional knowledge of renewable energy system design, while the last expert is a research associate with an energy research centre. Apart from the last expert who holds a M.Sc. degree in electrical and electronic engineering, the other experts are Ph.D. holders with specialization in renewable energy design and implementation.

This was done by administrating of the questionnaire to these experts. The questionnaire consists of two sections. The first section contained information about the effects of risks in the different energy sources. Section two contains information about the importance of mini-grid risks (Risk Questionnaire). Linguistic terms for Sections 1 and 2 responses are presented in Tables 3 (Figure 3 ) and 4 , respectively. The design requirements of the criteria are presented in Table 5.

Based on the information obtained from the decisionmakers (Table 6), it was only $C_{10}$ that they all assigned the 
TABLE 4: Linguistic terms for the risks importance.

\begin{tabular}{lc}
\hline Linguistic terms & Fuzzy numbers \\
\hline Extremely unimportant (EU) & $(0.30,0.50)$ \\
Unimportant (U) & $(0.40,0.35)$ \\
Indecisive (D) & $(0.50,0.25)$ \\
Important (I) & $(0.40,0.30)$ \\
Very important (V) & $(0.60,0.20)$ \\
Extremely important (E) & $(0.60,0.10)$ \\
\hline
\end{tabular}

TABLE 5: Design requirements for the criteria.

\begin{tabular}{lccc}
\hline Criteria & Design requirements & Criteria & Design requirements \\
\hline $\mathrm{C}_{1}$ & $\mathrm{~L}$ & $\mathrm{C}_{7}$ & $\mathrm{M}$ \\
$\mathrm{C}_{2}$ & $\mathrm{~L}$ & $\mathrm{C}_{8}$ & $\mathrm{~L}$ \\
$\mathrm{C}_{3}$ & $\mathrm{M}$ & $\mathrm{C}_{9}$ & $\mathrm{~L}$ \\
$\mathrm{C}_{4}$ & $\mathrm{~L}$ & $\mathrm{C}_{10}$ & $\mathrm{~L}$ \\
$\mathrm{C}_{5}$ & $\mathrm{M}$ & $\mathrm{C}_{12}$ & $\mathrm{M}$ \\
$\mathrm{C}_{6}$ & $\mathrm{M}$ & $\mathrm{C}_{12}$ & $\mathrm{M}$ \\
& & $\mathrm{C}_{13}$ & $\mathrm{M}$ \\
\hline
\end{tabular}

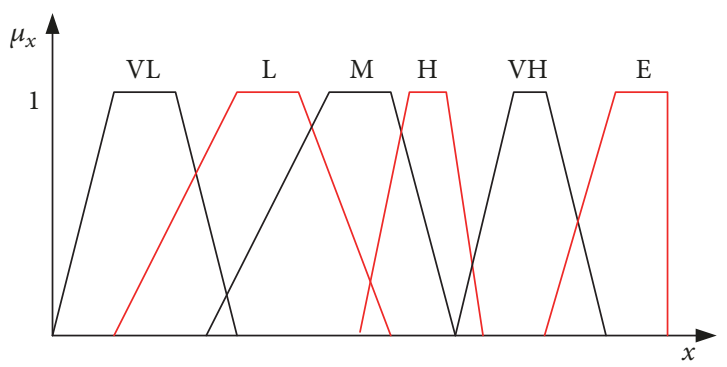

FIgURE 3: Membership functions for the effect of risk on mini-grid energy sources.

same importance to use the linguistic terms. The information in Table 6 was converted into membership values (Table 7).

The intuitionistic values obtained from the decisionmakers are used to generate the criteria importance in Table 8; this was achieved by applying (5) to (7). These results were combined with the values which the decisionmakers assigned to the energy sources (Table 9). Using (8) and (11), the decision-makers responses were aggregated, and the results that were obtained are presented in Table 10. This creates the avenue to generate the common (Table 11) and system (Table 12) areas for the alternatives.

The criteria information contents are obtained using (12) and the results obtained are presented in Table 13. Based on the weights in Table 8 this information was converted to the weighted information contents.

From Tables 14 and 15, the total information and weighted total information contents (Table 15) were obtained using (13). The results obtained showed that the criteria weights did not affect the ranking of the renewable energy sources (Table 15). Based on these results, the best-ranked renewable
TABLE 6: Linguistic terms for the weights importance.

\begin{tabular}{lcccc}
\hline Criteria & $\mathrm{D}_{1}$ & $\mathrm{D}_{2}$ & $\mathrm{D}_{3}$ & $\mathrm{D}_{4}$ \\
\hline $\mathrm{C}_{1}$ & $\mathrm{EU}$ & $\mathrm{I}$ & $\mathrm{U}$ & $\mathrm{I}$ \\
$\mathrm{C}_{2}$ & $\mathrm{VI}$ & $\mathrm{VI}$ & $\mathrm{VI}$ & $\mathrm{I}$ \\
$\mathrm{C}_{3}$ & $\mathrm{VI}$ & $\mathrm{VI}$ & $\mathrm{E}$ & $\mathrm{HU}$ \\
$\mathrm{C}_{4}$ & $\mathrm{U}$ & $\mathrm{I}$ & $\mathrm{D}$ & $\mathrm{U}$ \\
$\mathrm{C}_{5}$ & $\mathrm{I}$ & $\mathrm{D}$ & $\mathrm{VI}$ & $\mathrm{I}$ \\
$\mathrm{C}_{6}$ & $\mathrm{VI}$ & $\mathrm{D}$ & $\mathrm{I}$ & $\mathrm{U}$ \\
$\mathrm{C}_{7}$ & $\mathrm{E}$ & $\mathrm{I}$ & $\mathrm{VI}$ & $\mathrm{EI}$ \\
$\mathrm{C}_{8}$ & $\mathrm{VI}$ & $\mathrm{U}$ & $\mathrm{VI}$ & $\mathrm{VI}$ \\
$\mathrm{C}_{9}$ & $\mathrm{VI}$ & $\mathrm{D}$ & $\mathrm{I}$ & $\mathrm{U}$ \\
$\mathrm{C}_{10}$ & $\mathrm{I}$ & $\mathrm{I}$ & $\mathrm{I}$ & $\mathrm{I}$ \\
$\mathrm{C}_{11}$ & $\mathrm{I}$ & $\mathrm{E}$ & $\mathrm{I}$ & $\mathrm{VI}$ \\
$\mathrm{C}_{12}$ & $\mathrm{VI}$ & $\mathrm{I}$ & $\mathrm{VI}$ & $\mathrm{VI}$ \\
$\mathrm{C}_{13}$ & $\mathrm{VI}$ & $\mathrm{I}$ & $\mathrm{VI}$ & $\mathrm{I}$ \\
\hline
\end{tabular}

energy source was wind energy. The solar energy source was ranked as the least energy source.

The implementation of the fuzzy TOPSIS method is carried by first determining the normalised values of the criteria in Table 10. This was achieved by considering all the criteria as nonbenefit criteria (see (18)). The results obtained are presented in Table 16. These results were combined with the weights in Table 8 using (19) in generating the weighted normalised decision matrix for the fuzzy TOPSIS method (Table 17).

From Table 17, the distances of the criteria from the ideal and not-ideal solution were calculated using (22) and (23) and the results that are obtained in Table 18. Furthermore, (24) and (25) were used to combine these results in order to determine the energy sources closeness coefficients (Table 19).

In order to regularise the FAD framework results, a constant value was added to the actual values in Table 15. For this particular case, we added 1 to the FAD values in order to obtain the regularised FAD values (Table 20). This process was followed by the normalisation of the regularised FAD and fuzzy-TOPSIS results for the WASPAS method (Table 21).

Three cases were considered during the computation of the energy sources weighted sum and product for the WASPAS method (Table 22). Based on the information in Tables 20 and 21, the weighted sum and product values for the three cases were computed (Table 23). These values (Table 23) were used to generate the WASPAS outputs for the three cases (Table 24). The WASPAS values for the values cases were computed when the value of $\lambda=0.5$.

\section{Discussion of Results}

Based on the results in Table 8, the least and most important risks for the selection of renewable energy sources for mini-grid were unpredictable electricity demand risk and construction completion risk, respectively. Based on the decision-makers responses, there were several instances when a decision-maker assigned the same values of importance to a particular risk. The first decision-maker believed 
TABLE 7: Intuitionistic sets for the criteria importance.

\begin{tabular}{lcccc}
\hline Criteria & $\mathrm{D}_{1}$ & $\mathrm{D}_{2}$ & $\mathrm{D}_{3}$ & $\mathrm{D}_{4}$ \\
\hline $\mathrm{C}_{1}$ & $(0.3000,0.5000)$ & $(0.4000,0.3000)$ & $(0.4000,0.3500)$ & $(0.4000,0.3000)$ \\
$\mathrm{C}_{2}$ & $(0.6000,0.2000)$ & $(0.6000,0.2000)$ & $(0.6000,0.2000)$ & $(0.4000,0.3000)$ \\
$\mathrm{C}_{3}$ & $(0.6000,0.2000)$ & $(0.6000,0.2000)$ & $(0.6000,0.1000)$ & $(0.3000,0.5000)$ \\
$\mathrm{C}_{4}$ & $(0.4000,0.3500)$ & $(0.4000,0.3000)$ & $(0.5000,0.2500)$ & $(0.4000,0.3500)$ \\
$\mathrm{C}_{5}$ & $(0.4000,0.3000)$ & $(0.5000,0.2500)$ & $(0.6000,0.2000)$ & $(0.4000,0.3000)$ \\
$\mathrm{C}_{6}$ & $(0.6000,0.2000)$ & $(0.5000,0.2500)$ & $(0.4000,0.3000)$ & $(0.4000,0.3500)$ \\
$\mathrm{C}_{7}$ & $(0.6000,0.1000)$ & $(0.4000,0.3000)$ & $(0.6000,0.2000)$ & $(0.6000,0.1000)$ \\
$\mathrm{C}_{8}$ & $(0.6000,0.2000)$ & $(0.4000,0.3500)$ & $(0.6000,0.2000)$ & $(0.6000,0.2000)$ \\
$\mathrm{C}_{9}$ & $(0.6000,0.2000)$ & $(0.5000,0.2500)$ & $(0.4000,0.3000)$ & $(0.4000,0.3500)$ \\
$\mathrm{C}_{10}$ & $(0.4000,0.3000)$ & $(0.4000,0.3000$ & $(0.4000,0.3000)$ & $(0.4000,0.3000)$ \\
$\mathrm{C}_{11}$ & $(0.4000,0.3000)$ & $(0.6000,0.1000)$ & $(0.4000,0.3000)$ & $(0.6000,0.2000)$ \\
$\mathrm{C}_{12}$ & $(0.6000,0.2000)$ & $(0.4000,0.3000)$ & $(0.6000,0.2000)$ & $(0.6000,0.2000)$ \\
$\mathrm{C}_{13}$ & $(0.6000,0.2000)$ & $(0.4000,0.3000)$ & $(0.6000,0.2000)$ & $(0.4000,0.3000)$ \\
\hline
\end{tabular}

TABLE 8: Importance of the selection criteria.

\begin{tabular}{lccr}
\hline Criteria & $E_{L T}^{I F S}$ & $d_{j}$ & $w_{j}$ \\
\hline$C_{1}$ & 0.5765 & 0.4235 & 0.0788 \\
$C_{2}$ & 0.4667 & 0.5333 & 0.0992 \\
$C_{3}$ & 0.5069 & 0.4931 & 0.0917 \\
$C_{4}$ & 0.5829 & 0.4171 & 0.0776 \\
$C_{5}$ & 0.6199 & 0.3801 & 0.0707 \\
$C_{6}$ & 0.5490 & 0.4510 & 0.0839 \\
$C_{7}$ & 0.8137 & 0.1863 & 0.0347 \\
$C_{8}$ & 0.3958 & 0.6042 & 0.1124 \\
$C_{9}$ & 0.5490 & 0.4510 & 0.0839 \\
$C_{10}$ & 0.7806 & 0.2194 & 0.0408 \\
$C_{11}$ & 0.7448 & 0.2552 & 0.0475 \\
$C_{12}$ & 0.4667 & 0.5333 & 0.0992 \\
$C_{13}$ & 0.5713 & 0.4287 & 0.0797 \\
\hline
\end{tabular}

resource price variability and nonpayment of electricity bills risks are the same for the renewable energy sources. The second decision-maker assigned the same values to theft and vandalism risk and foreign exchange risk. The third decision-maker only agreed that the risks associated with political and legal (regulatory) risks were the same (Table 9). The fourth decision-maker assigned the same value for the environmental risk.

In terms of ranking of the energy sources, the results obtained showed that there was no change in the ranking order for the renewable energy sources for the different cases that were considered in this study (see Table 24). Furthermore, there was consistency between FAD and WASPAS ranking order (see Figure 4). Looking at Figure 4, the bestranked renewable energy source for the mini-grid business using the FAD conceptual framework was wind energy. This result is not the same as that of the fuzzy-TOPSIS method which ranked biomass energy as the best renewable energy sources for the mini-grid business.

\section{Conclusions}

This study demonstrated the applicability of using a combined intuitionistic entropy-FAD and intuitionistic entropyTOPSIS frameworks to address the problem of renewable energy source selection for mini-grid business in developing countries. The selection process was carried out using thirteen types of risk that are associated with mini-grid operations, economics, design, and management. The frameworks were applied in a developed country in sub-Sahara Africa. Four experts' inputs were obtained using a structured questionnaire.

The conceptual framework for mini-grid business renewable energy source selection appears to be a flexible tool for decision-making in a developing economy. There is a discrepancy between the FAD principle and fuzzy-TOPSIS frameworks. The best-ranked renewable energy source for the case study using the FAD framework was wind energy. The fuzzy-TOPSIS framework identified biomass energy as the 


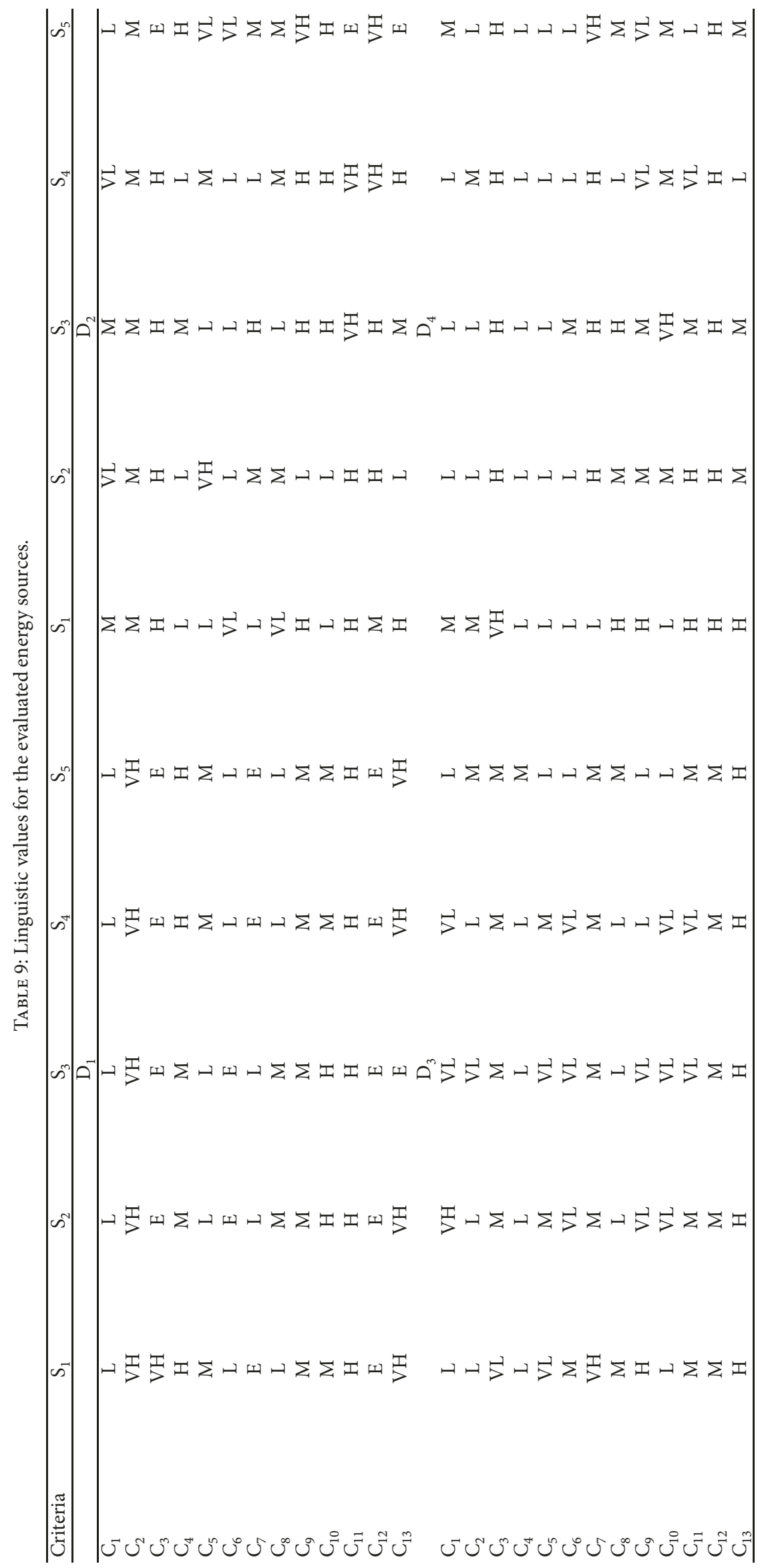




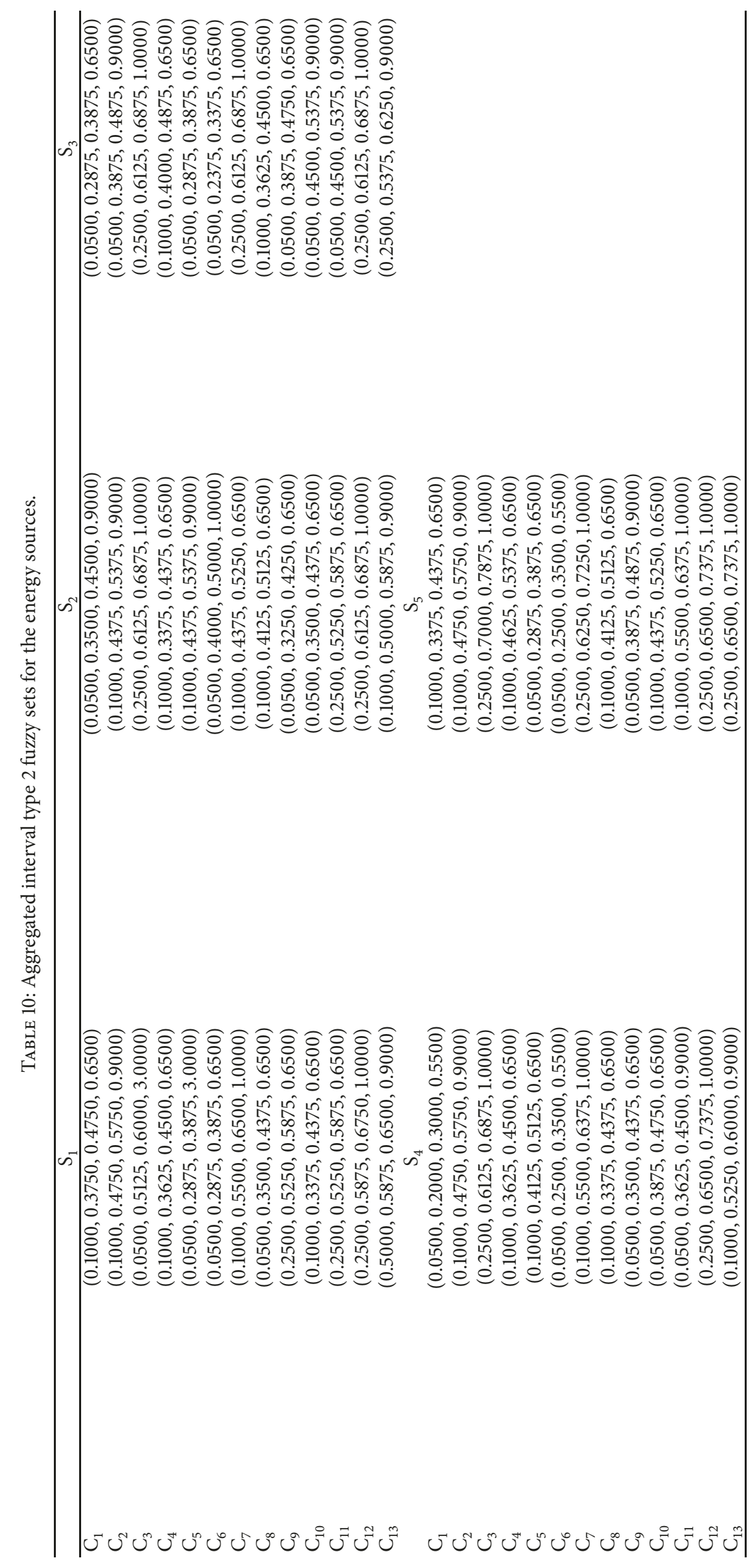


TABLE 11: Common area for the maintenance systems.

\begin{tabular}{lcccrr}
\hline Criteria & $\mathrm{S}_{1}$ & $\mathrm{~S}_{2}$ & $\mathrm{~S}_{3}$ & $\mathrm{~S}_{4}$ & $\mathrm{~S}_{5}$ \\
\hline $\mathrm{C}_{1}$ & 0.3184 & 0.4267 & 0.2689 & 0.1841 & 0.2951 \\
$\mathrm{C}_{2}$ & 0.5120 & 0.4830 & 0.4491 & 0.5120 & 0.5120 \\
$\mathrm{C}_{3}$ & 1.4070 & 0.4787 & 0.4787 & 0.3103 & 0.5625 \\
$\mathrm{C}_{4}$ & 0.3103 & 0.2951 & 0.3361 & 0.1829 & 0.3903 \\
$\mathrm{C}_{5}$ & 1.2983 & 0.3189 & 0.1422 & 0.0900 & 0.1422 \\
$\mathrm{C}_{6}$ & 0.1422 & 0.3516 & 0.1306 & 0.4327 & 0.0900 \\
$\mathrm{C}_{7}$ & 0.4327 & 0.1939 & 0.4787 & 0.2951 & 0.4891 \\
$\mathrm{C}_{8}$ & 0.3025 & 0.3457 & 0.3103 & 0.3025 & 0.3457 \\
$\mathrm{C}_{9}$ & 0.4654 & 0.2881 & 0.3270 & 0.3270 & 0.4491 \\
$\mathrm{C}_{10}$ & 0.2951 & 0.3025 & 0.4923 & 0.2864 \\
$\mathrm{C}_{11}$ & 0.2462 & 0.2462 & 0.3250 & 0.3114 \\
$\mathrm{C}_{12}$ & 0.4592 & 0.4787 & 0.4787 & 0.3667 \\
$\mathrm{C}_{13}$ & 0.4122 & 0.3521 & 0.3756 & 0.4327 \\
\hline
\end{tabular}

TABLE 12: System area for the maintenance systems.

\begin{tabular}{lcccrr}
\hline Criteria & $\mathrm{S}_{1}$ & $\mathrm{~S}_{2}$ & $\mathrm{~S}_{3}$ & $\mathrm{~S}_{4}$ & 0.3000 \\
\hline $\mathrm{C}_{1}$ & 0.3250 & 0.4750 & 0.3500 & 0.4500 & 0.3250 \\
$\mathrm{C}_{2}$ & 0.4500 & 0.4500 & 0.4750 & 0.4125 & 0.4500 \\
$\mathrm{C}_{3}$ & 1.5188 & 0.4125 & 0.4125 & 0.3188 & 0.4188 \\
$\mathrm{C}_{4}$ & 0.3188 & 0.3250 & 0.3188 & 0.3250 & 0.3125 \\
$\mathrm{C}_{5}$ & 1.5250 & 0.4500 & 0.3500 & 0.3000 & 0.3500 \\
$\mathrm{C}_{6}$ & 0.3500 & 0.5250 & 0.3500 & 0.4938 & 0.3000 \\
$\mathrm{C}_{7}$ & 0.5000 & 0.3188 & 0.4125 & 0.3250 & 0.4250 \\
$\mathrm{C}_{8}$ & 0.3438 & 0.3250 & 0.3188 & 0.3438 & 0.3250 \\
$\mathrm{C}_{9}$ & 0.2313 & 0.3500 & 0.3438 & 0.3438 \\
$\mathrm{C}_{10}$ & 0.3250 & 0.3438 & 0.4688 & 0.4688 \\
$\mathrm{C}_{11}$ & 0.2313 & 0.2313 & 0.4688 & 0.4188 \\
$\mathrm{C}_{12}$ & 0.4188 & 0.4125 & 0.4125 & 0.3188 \\
$\mathrm{C}_{13}$ & 0.2313 & 0.4438 & 0.3688 & 0.4375 \\
\hline
\end{tabular}

TABLE 13: Information contents of the criteria with respect to the maintenance systems.

\begin{tabular}{lccccc}
\hline Criteria & $\mathrm{S}_{1}$ & $\mathrm{~S}_{2}$ & $\mathrm{~S}_{3}$ & $\mathrm{~S}_{4}$ & 0.7045 \\
\hline $\mathrm{C}_{1}$ & 0.0295 & 0.1548 & 0.3803 & -0.1862 & -1391 \\
$\mathrm{C}_{2}$ & -0.1862 & -0.1022 & 0.0808 & -0.2148 & -0.1862 \\
$\mathrm{C}_{3}$ & 0.1103 & -0.2148 & -0.2148 & 0.0390 & -0.4258 \\
$\mathrm{C}_{4}$ & 0.0390 & 0.1391 & -0.0765 & 0.8297 & -0.3208 \\
$\mathrm{C}_{5}$ & 0.2322 & 0.4970 & 1.2992 & 1.7370 & 1.2992 \\
$\mathrm{C}_{6}$ & 1.2992 & 0.5785 & 1.4221 & 0.1904 & 1.7370 \\
$\mathrm{C}_{7}$ & 0.2086 & 0.7168 & -0.2148 & 0.1391 & -0.2028 \\
$\mathrm{C}_{8}$ & 0.1844 & -0.0891 & 0.0390 & 0.1844 & -0.0891 \\
$\mathrm{C}_{9}$ & -1.0090 & 0.2808 & 0.0719 & 0.0719 & 0.0808 \\
$\mathrm{C}_{10}$ & 0.1391 & 0.1844 & -0.0707 & 0.7106 & -0.2020 \\
$\mathrm{C}_{11}$ & -0.0901 & -0.0901 & 0.5284 & -0.2883 \\
$\mathrm{C}_{12}$ & -0.1330 & -0.2148 & -0.2148 & -0.1904 \\
$\mathrm{C}_{13}$ & -0.8339 & 0.3338 & -0.0264 & -0.2520 \\
\hline
\end{tabular}




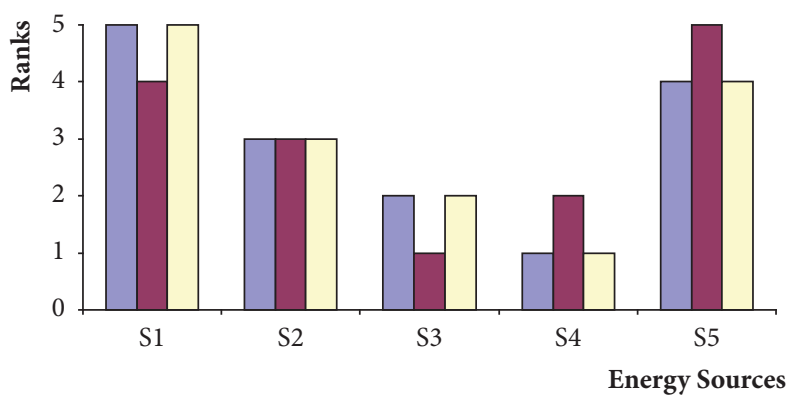

- FAD

- Fuzzy TOPSIS

- WASPAS

FIGURE 4: Ranking of energy sources using the different methods.

TABLE 14: Weighted information contents of the criteria with respect to the maintenance systems.

\begin{tabular}{lccccc}
\hline Criteria & $\mathrm{S}_{1}$ & $\mathrm{~S}_{2}$ & $\mathrm{~S}_{3}$ & $\mathrm{~S}_{4}$ & 0.0555 \\
$\mathrm{C}_{1}$ & 0.0023 & 0.0122 & 0.0300 & -0.0185 & 0.0110 \\
$\mathrm{C}_{2}$ & -0.0185 & -0.0101 & 0.0080 & -0.0197 & -0.0185 \\
$\mathrm{C}_{3}$ & 0.0101 & -0.0197 & -0.0197 & 0.0030 & -0.0390 \\
$\mathrm{C}_{4}$ & 0.0030 & 0.0108 & -0.0059 & 0.0587 & -0.0249 \\
$\mathrm{C}_{5}$ & 0.0164 & 0.0351 & 0.0919 & 0.1457 & 0.0919 \\
$\mathrm{C}_{6}$ & 0.1090 & 0.0485 & 0.1193 & 0.0066 & 0.1457 \\
$\mathrm{C}_{7}$ & 0.0072 & 0.0249 & -0.0075 & 0.0156 & -0.0070 \\
$\mathrm{C}_{8}$ & 0.0207 & -0.0100 & 0.0044 & 0.0155 & -0.0100 \\
$\mathrm{C}_{9}$ & -0.0847 & 0.0236 & 0.0060 & 0.0029 & 0.0068 \\
$\mathrm{C}_{10}$ & 0.0057 & 0.0075 & -0.0029 & 0.0338 & -0.0082 \\
$\mathrm{C}_{11}$ & -0.0043 & -0.0043 & 0.0251 & -0.0286 \\
$\mathrm{C}_{12}$ & -0.0132 & -0.0213 & -0.0213 & 0.0201 \\
$\mathrm{C}_{13}$ & -0.0665 & 0.0266 & -0.0021 & -0.0286 \\
\hline
\end{tabular}

TABLE 15: Total information contents.

\begin{tabular}{lcc}
\hline Sources & Total information contents & Total weighted information contents \\
\hline $\mathrm{S}_{1}$ & -0.0098 & -0.0125 \\
$\mathrm{~S}_{2}$ & 2.1743 & 0.1238 \\
$\mathrm{~S}_{3}$ & 3.0037 & 0.2253 \\
$\mathrm{~S}_{4}$ & 4.1694 & 0.2907 \\
$\mathrm{~S}_{5}$ & 1.4433 & 0.1051 \\
\hline
\end{tabular}

best-ranked renewable energy sources for the case study of a renewable energy source. The least and most important risks for the selection of renewable energy sources for mini-grid were unpredictable electricity demand risk and construction completion risk, respectively.

The use of FAD for the selection of a renewable energy source for mini-grid business is a contribution of this study. Furthermore, the application of fuzzy-TOPSIS for mini-grid business renewable energy selection is also a contribution of this study. Another contribution of this study is the application of the intuitionistic entropy method to determine the importance of risks that affect mini-grid business. The proposed conceptual framework can be applied to determine a mini-grid business model for a developing economy.
This study is subjected to at least two limitations, The first limitation of this study is that it did not consider the energy generation capacity of the renewable energy sources. Another limitation is that it did not consider life-cycle cost. This cost is a major factor in renewable energy sources evaluation. Also, this study did not consider the importance of the experts' judgments. Incorporating these omissions into the proposed framework will not only improve the viability of a selected renewable energy source, but also aid renewable energy plant's retirement decision. While the inclusion of social criteria into the proposed framework is a natural way to improve its performance, there is still a need to introduce carbon footprint in the proposed framework. These knowledge gaps can be considered as further studies. Finally, 


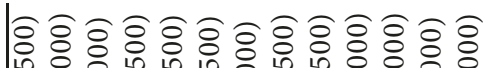

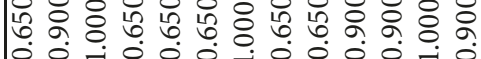

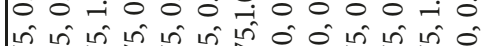

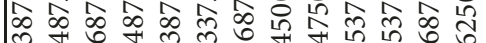

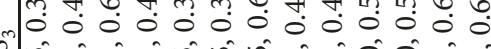

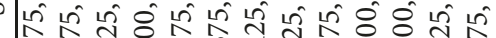

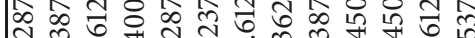

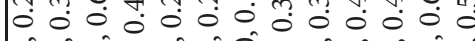

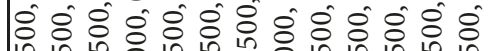

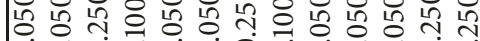

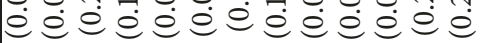

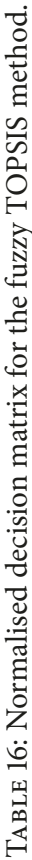

จิेoิ̀)

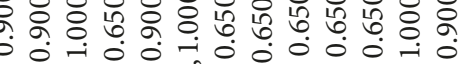

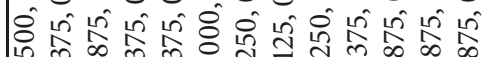

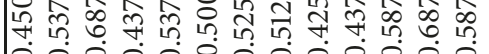

की

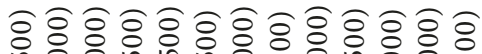

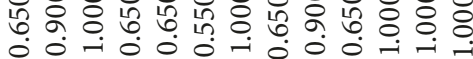

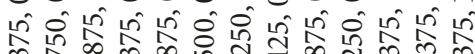

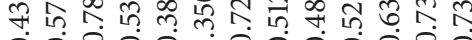
ผ फ के ले क्ष

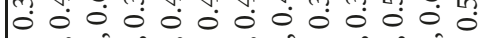

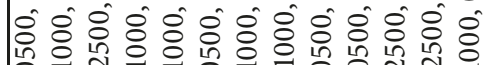

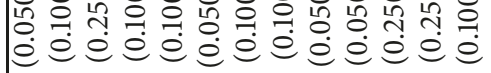
mर

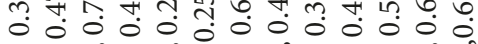

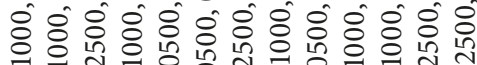

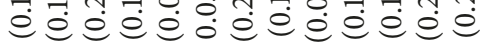

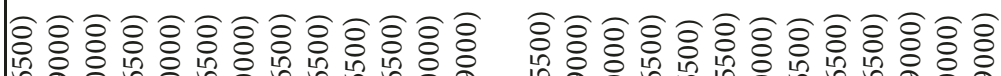

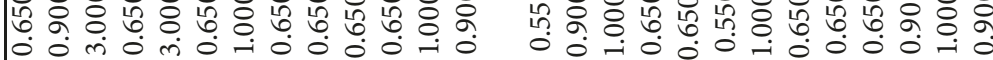

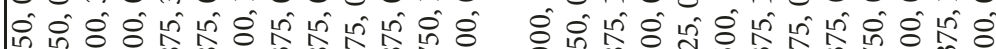

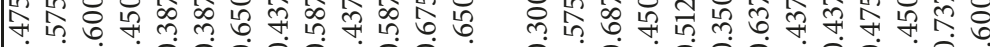

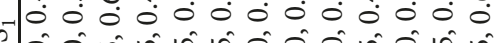

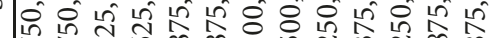

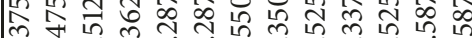

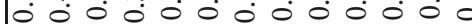

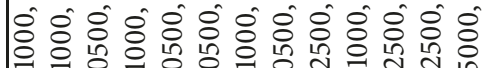 eे巳è ô की nी

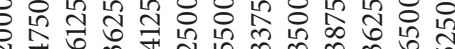

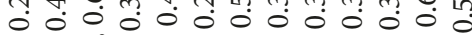

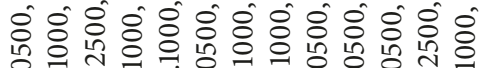

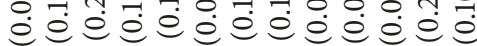




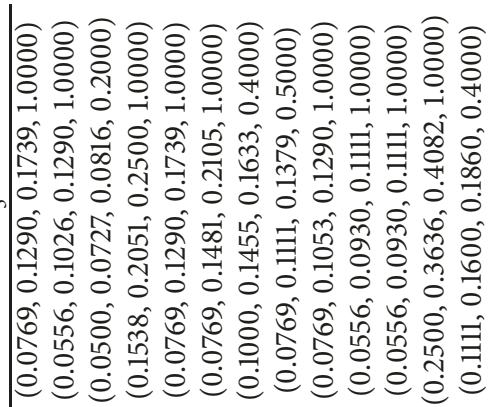



ิิ) 行

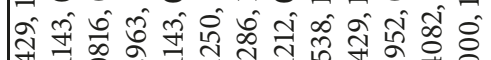

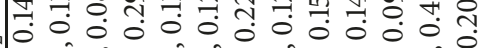

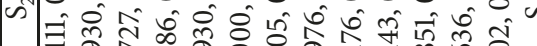

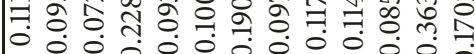
r 00000000000

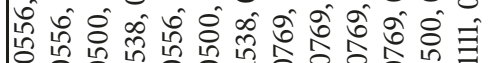

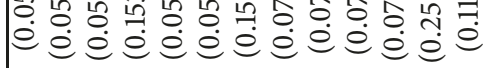

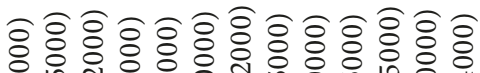

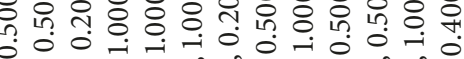

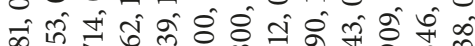

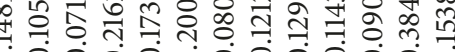
000100000 भิ

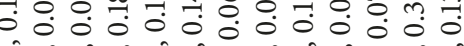

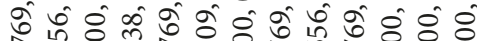

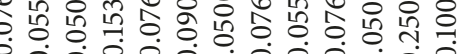

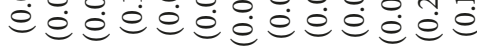

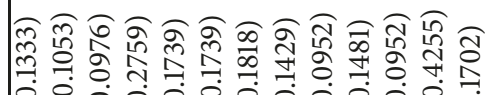

จิธิ์ 0 0 0000000000000

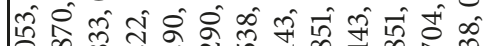

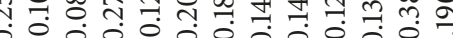
on

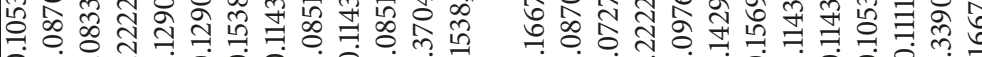

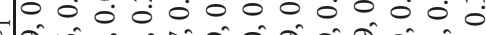

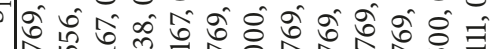
它

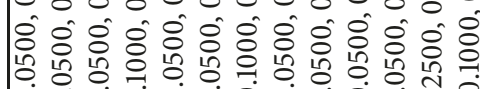

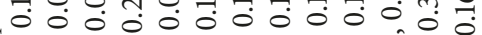

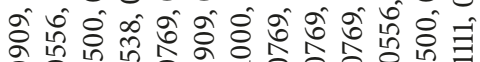

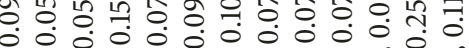

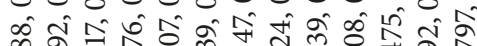

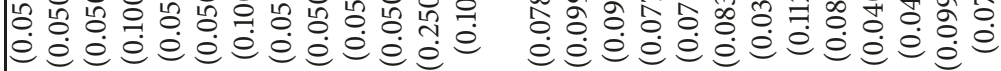




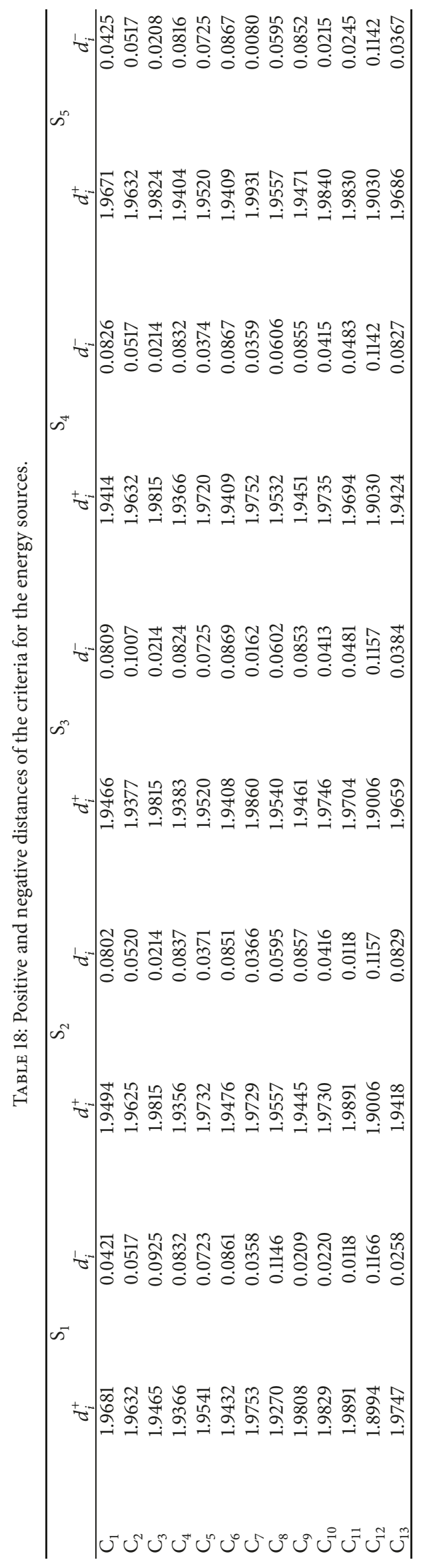


TABLE 19: Fuzzy TOPSIS outputs for the mini-grid energy sources problem.

\begin{tabular}{lccr}
\hline Sources & $D_{i}^{+}$ & $D_{i}^{-}$ & $C_{i}$ \\
\hline $\mathrm{S}_{1}$ & 25.4410 & 0.7755 & 0.0296 \\
$\mathrm{~S}_{2}$ & 25.4274 & 0.7933 & 0.0303 \\
$\mathrm{~S}_{3}$ & 25.3944 & 0.8501 & 0.0324 \\
$\mathrm{~S}_{4}$ & 25.3975 & 0.8317 & 0.0317 \\
$\mathrm{~S}_{5}$ & 25.4805 & 0.7055 & 0.0269 \\
\hline
\end{tabular}

TABLE 20: Decision matrix for the WASPAS method.

\begin{tabular}{lccc}
\hline Sources & FAD & Regularised FAD & Fuzzy TOPSIS \\
\hline $\mathrm{S}_{1}$ & -0.0125 & 0.9875 & 0.0296 \\
$\mathrm{~S}_{2}$ & 0.1238 & 1.1238 & 0.0303 \\
$\mathrm{~S}_{3}$ & 0.2253 & 1.2253 & 0.0324 \\
$\mathrm{~S}_{4}$ & 0.2907 & 1.2907 & 0.0317 \\
$\mathrm{~S}_{5}$ & 0.1051 & 1.1051 & 0.0269 \\
\hline
\end{tabular}

TABLE 21: Normalisation decision matrix for the WASPAS method.

\begin{tabular}{lcc}
\hline Sources & Normalised FAD & Fuzzy TOPSIS \\
\hline $\mathrm{S}_{1}$ & 0.3788 & 0.0129 \\
$\mathrm{~S}_{2}$ & 0.4906 & 0.0135 \\
$\mathrm{~S}_{3}$ & 0.5832 & 0.0155 \\
$\mathrm{~S}_{4}$ & 0.6472 & 0.0149 \\
$\mathrm{~S}_{5}$ & 0.4744 & 0.0107 \\
\hline
\end{tabular}

TABLE 22: Weights for the solution methods.

\begin{tabular}{lcc}
\hline Cases & Normalised FAD & Fuzzy TOPSIS \\
\hline Case I & $\omega_{1}=0.6$ & $\omega_{2}=0.4$ \\
Case II & $\omega_{1}=0.4$ & $\omega_{2}=0.5$ \\
Case III & $\omega_{1}=0.6$ & $\omega_{2}=0.6$ \\
\hline
\end{tabular}

TABLE 23: Weighted sum and product for the cases.

\begin{tabular}{lccccrr}
\hline Sources & \multicolumn{2}{c}{ Case I } & \multicolumn{2}{c}{ Case II } & \multicolumn{2}{c}{ Case III } \\
& $Q_{i}^{+}$ & $Q_{i}^{-}$ & $Q_{i}^{+}$ & $Q_{i}^{-}$ & $Q_{i}^{+}$ \\
\hline $\mathrm{S}_{1}$ & 0.2325 & 0.0981 & 0.1959 & 0.0700 & 0.1593 \\
$\mathrm{~S}_{2}$ & 0.2998 & 0.1167 & 0.2521 & 0.0815 & 0.0500 \\
$\mathrm{~S}_{3}$ & 0.3561 & 0.1367 & 0.2994 & 0.0951 & 0.2044 & 0.0569 \\
$\mathrm{~S}_{4}$ & 0.3942 & 0.1431 & 0.3310 & 0.0981 & 0.2678 \\
$\mathrm{~S}_{5}$ & 0.2889 & 0.1042 & 0.2426 & 0.0714 & 0.1962 & 0.0673 \\
\hline
\end{tabular}

TABLE 24: WASPAS outputs.

\begin{tabular}{llll}
\hline Sources & Case I & Case II & Case III \\
\hline $\mathrm{S}_{1}$ & 0.1653 & 0.1330 & 0.1046 \\
$\mathrm{~S}_{2}$ & 0.2082 & 0.1668 & 0.1306 \\
$\mathrm{~S}_{3}$ & 0.2464 & 0.1973 & 0.1544 \\
$\mathrm{~S}_{4}$ & 0.2687 & 0.2146 & 0.1675 \\
$\mathrm{~S}_{5}$ & 0.1966 & 0.1570 & 0.1225 \\
\hline
\end{tabular}


all the data that were used in this paper are already included in the manuscript in the Data Availability section.

\section{Data Availability}

The data used to support the findings of this study are included within the article.

\section{Conflicts of Interest}

The authors declare that they have no conflicts of interest.

\section{References}

[1] IRENA, "Off-grid Renewable Energy Systems: Status and Methodological Issues," in Proceedings of the International Renewable Energy Agency, Abu Dhabi, UA, 2015.

[2] S. Bhattacharyya, "Mini-Grids for the Base of the Pyramid Market: A Critical Review," Energies, vol. 11, no. 4, p. 813, 2018.

[3] J. San Cristóbal, "Multi-criteria decision-making in the selection of a renewable energy project in spain: the Vikor method," Journal of Renewable Energy, vol. 36, no. 2, pp. 498-502, 2011.

[4] S. D. Pohekar and M. Ramachandran, "Application of multicriteria decision making to sustainable energy planning-a review," Renewable \& Sustainable Energy Reviews, vol. 8, no. 4, pp. 365-381, 2004.

[5] E. Georgopoulou, D. Lalas, and L. Papagiannakis, "A Multicriteria Decision Aid approach for energy planning problems: The case of renewable energy option," European Journal of Operational Research, vol. 103, no. 1, pp. 38-54, 1997.

[6] C. Kahraman and I. Kaya, "A fuzzy multicriteria methodology for selection among energy alternatives," Expert Systems with Applications, vol. 37, no. 9, pp. 6270-6281, 2010.

[7] D. A. Haralambopoulos and H. Polatidis, "Renewable energy projects: Structuring a multi-criteria group decision-making framework," Journal of Renewable Energy, vol. 28, no. 6, pp. 961973, 2003.

[8] M. Martín-Gamboa, D. Iribarren, D. García-Gusano, and J. Dufour, "A review of life-cycle approaches coupled with data envelopment analysis within multi-criteria decision analysis for sustainability assessment of energy systems," Journal of Cleaner Production, vol. 150, pp. 164-174, 2017.

[9] A. Kumar, B. Sah, A. R. Singh et al., "A review of multi criteria decision making (MCDM) towards sustainable renewable energy development," Renewable \& Sustainable Energy Reviews, vol. 69, pp. 596-609, 2017.

[10] J.-J. Wang, Y.-Y. Jing, C.-F. Zhang, and J.-H. Zhao, "Review on multi-criteria decision analysis aid in sustainable energy decision-making," Renewable \& Sustainable Energy Reviews, vol. 13, no. 9, pp. 2263-2278, 2009.

[11] Ü. Sengül, M. Eren, S. E. Shiraz, V. Gezder, and A. B. Sengül, "Fuzzy TOPSIS method for ranking renewable energy supply systems in Turkey," Journal of Renewable Energy, vol. 75, pp. 617625, 2015.

[12] M. Alsayed, M. Cacciato, G. Scelba, and A. Consoli, "Optimal sizing of hybrid power generation systems based on multi criteria decision analysis," in Proceedings of the 21st International Symposium on Power Electronics, Electrical Drives, Automation and Motion, SPEEDAM 2012, pp. 1442-1447, Italy, June 2012.
[13] C. Kahraman, I. Kaya, and S. Cebi, "A comparative analysis for multiattribute selection among renewable energy alternatives using fuzzy axiomatic design and fuzzy analytic hierarchy process," Energy, vol. 34, no. 10, pp. 1603-1616, 2009.

[14] H. Polatidis and D. A. Haralambopoulos, "Local renewable energy planning: A participatory multi-criteria approach," Energy Sources, vol. 26, no. 13, pp. 1253-1264, 2004.

[15] D. Streimikiene, J. Sliogeriene, and Z. Turskis, "Multi-criteria analysis of electricity generation technologies in Lithuania," Journal of Renewable Energy, vol. 85, pp. 148-156, 2016.

[16] A. Mardani, E. K. Zavadskas, Z. Khalifah et al., "A review of multi-criteria decision-making applications to solve energy management problems: two decades from 1995 to 2015," Renewable \& Sustainable Energy Reviews, vol. 71, pp. 216-256, 2017.

[17] S. Malkawi, M. Al-Nimr, and D. Azizi, "A multi-criteria optimization analysis for Jordan's energy mix," Energy, vol. 127, pp. 680-696, 2017.

[18] T. Tsoutsos, M. Drandaki, N. Frantzeskaki, E. Iosifidis, and I. Kiosses, "Sustainable energy planning by using multi-criteria analysis application in the island of Crete," Energy Policy, vol. 37, no. 5, pp. 1587-1600, 2009.

[19] A. Mardani, E. K. Zavadskas, D. Streimikiene, A. Jusoh, K. M. D. Nor, and M. Khoshnoudi, "Using fuzzy multiple criteria decision making approaches for evaluating energy saving technologies and solutions in five star hotels: A new hierarchical framework," Energy, vol. 117, pp. 131-148, 2016.

[20] S. Onut, U. R. Tuzkaya, and N. Saadet, "Multiple criteria evaluation of current energy resources for Turkish manufacturing industry," Energy Conversion and Management, vol. 49, no. 6, pp. 1480-1492, 2008.

[21] P. R. Krithika and D. Palit, "Participatory Business Models for Off-Grid Electrification," in Rural Electrification Through Decentralised Off-grid Systems in Developing Countries, Green Energy and Technology, pp. 187-225, Springer, London, 2013.

[22] UNDP, "Solar photovoltaics in Africa: Experiences with financing and delivery models," 2004.

[23] T. O. Akinbulire, P. O. Oluseyi, and O. M. Babatunde, “Technoeconomic and environmental evaluation of demand side management techniques for rural electrification in Ibadan, Nigeria," International Journal of Energy and Environmental Engineering, vol. 5, no. 4, pp. 375-385, 2014.

[24] World Bank, "Designing Sustainable Off-Grid Rural Electrification Projects: Principles and Practices," 2008, http://www .worldbank.org/energy.

[25] IEA, "Comparative Study on Rural Electrification Policies in Emerging Economies," in Proceedings of the International Energy Agency, Paris, 2010.

[26] D. F. Barnes, “The Challenge of Rural Electrification,” ESMAP Report, World Bank, Washington, DC, USA, 2005.

[27] T. Urmee, D. Harries, and A. Schlapfer, "Issues related to rural electrification using renewable energy in developing countries of Asia and Pacific," Journal of Renewable Energy, vol. 34, no. 2, pp. 354-357, 2009.

[28] S. Karekezi, S. Meyers, L. Majoro, J. Kimani, and A. Wambille, "Energy Access Working Group Global Network on Energy for Sustainable Development," Final Synthesis/Compilation Report for the Policy Implementation Phase, 2006.

[29] X. Lemaire, "Fee-for-service companies for rural electrification with photovoltaic systems: the case of Zambia," Energy for Sustainable Development, vol. 13, no. 1, pp. 18-23, 2009. 
[30] O. Mfune and E. K. Boon, "Promoting Renewable Energy Technologies for Rural Development in Africa: Experiences of Zambia," Journal of Human Ecology, vol. 24, no. 3, pp. 175-189, 2008.

[31] S. Khennas and A. Barnett, Best Practices for Sustainable Development of Micro Hydro Power in Developing Countries, DFID, UK, 2000.

[32] D. Palit and A. Chaurey, "Off-grid rural electrification experiences from South Asia: Status and best practices," Energy for Sustainable Development, vol. 15, no. 3, pp. 266-276, 2011.

[33] D. Singh, Renewable Energy for Village Electrification, Goldline, New Delhi, 1997.

[34] W. Van Nes and M. Mendis, "Biogas in rural household energy supply: the Nepal biogas support program," Energy for Sustainable Development, vol. 3, no. 2, pp. 100-113, 2000.

[35] S. Gitonga, Biogas Promotion in Kenya: A Review of Experiences, Intermed. Technol. Dev. Group, Nairobi, Kenya, 1997.

[36] S. Karekesi and T. Ranja, Renewable Energy Technologies in Africa, Zed Book, London, 1997.

[37] S. H. Zanakis, A. Solomon, N. Wishart, and S. Dublish, "Multiattribute decision making: a simulation comparison of select methods," European Journal of Operational Research, vol. 107, no. 3, pp. 507-529, 1998.

[38] S. Cheng, C. W. Chan, and G. H. Huang, "Using multiple criteria decision analysis for supporting decisions of solid waste management," Journal of Environmental Science and Health, Part A: Toxic/Hazardous Substances and Environmental Engineering, vol. 37, no. 6, pp. 975-990, 2002.

[39] E. K. Zavadskas, Z. Turskis, and J. Antucheviciene, "Selecting a contractor by using a novel method for multiple attribute analysis: Weighted aggregated sum product assessment with grey values (WASPAS-G)," Studies in Informatics and Control, vol. 24, no. 2, pp. 141-150, 2015.

[40] C. C. Hung and L. H. Chen, "A Fuzzy TOPSIS Decision Making Model with Entropy Weight under Intuitionistic Fuzzy Environment," in Proceedings of the International MultiConference of Engineers and Computer Scientists 2009, . IMECS, vol. 1, Hong Kong, 2009.

[41] A. V. Khandekar and S. Chakraborty, "Selection of material handling equipment using fuzzy axiomatic design principles," Informatica, vol. 26, no. 2, pp. 259-282, 2015.

[42] D. E. Ighravwe and S. A. Oke, "Ranking maintenance strategies for sustainable maintenance plan in manufacturing systems using fuzzy axiomatic design principle and fuzzy-TOPSIS," Journal of Manufacturing Technology Management, vol. 28, no. 7, pp. 961-992, 2017.

[43] K. Yoon and C. L. Hwang, Multiple Attribute Decision Making: Methods and Applications, vol. 186, Springer, Heidelberg, Germany, 1981.

[44] Y.-J. Lai, T.-Y. Liu, and C.-L. Hwang, "TOPSIS for MODM," European Journal of Operational Research, vol. 76, no. 3, pp. 486-500, 1994.

[45] C. Chen, "Extensions of the TOPSIS for group decision-making under fuzzy environment," Fuzzy Sets and Systems, vol. 114, no. 1, pp. 1-9, 2000.

[46] T. Kaya and C. Kahraman, "Multicriteria decision making in energy planning using a modified fuzzy TOPSIS methodology," Expert Systems with Applications, vol. 38, no. 6, pp. 6577-6585, 2011.
[47] E. Roszkowska, "Multi-criteria decision making models by applying the TOPSIS method to crisp and interval data," in Multiple Criteria Decision Making, vol. 6, pp. 200-230, University of Economics in Katowice, 2011.

[48] M. S. García-Cascales and M. T. Lamata, "On rank reversal and TOPSIS method," Mathematical and Computer Modelling, vol. 56, no. 5-6, pp. 123-132, 2012.

[49] N. I. Nwulua and O. P. Agboola, "Utilizing renewable energy resources to solve Nigeria's electricity generation problem," International Journal of Thermal \& Environmental Engineering, vol. 3, no. 1, pp. 15-20, 2011.

[50] J. Ben-Iwo, V. Manovic, and P. Longhurst, "Biomass resources and biofuels potential for the production of transportation fuels in Nigeria," Renewable \& Sustainable Energy Reviews, vol. 63, pp. 172-192, 2016. 

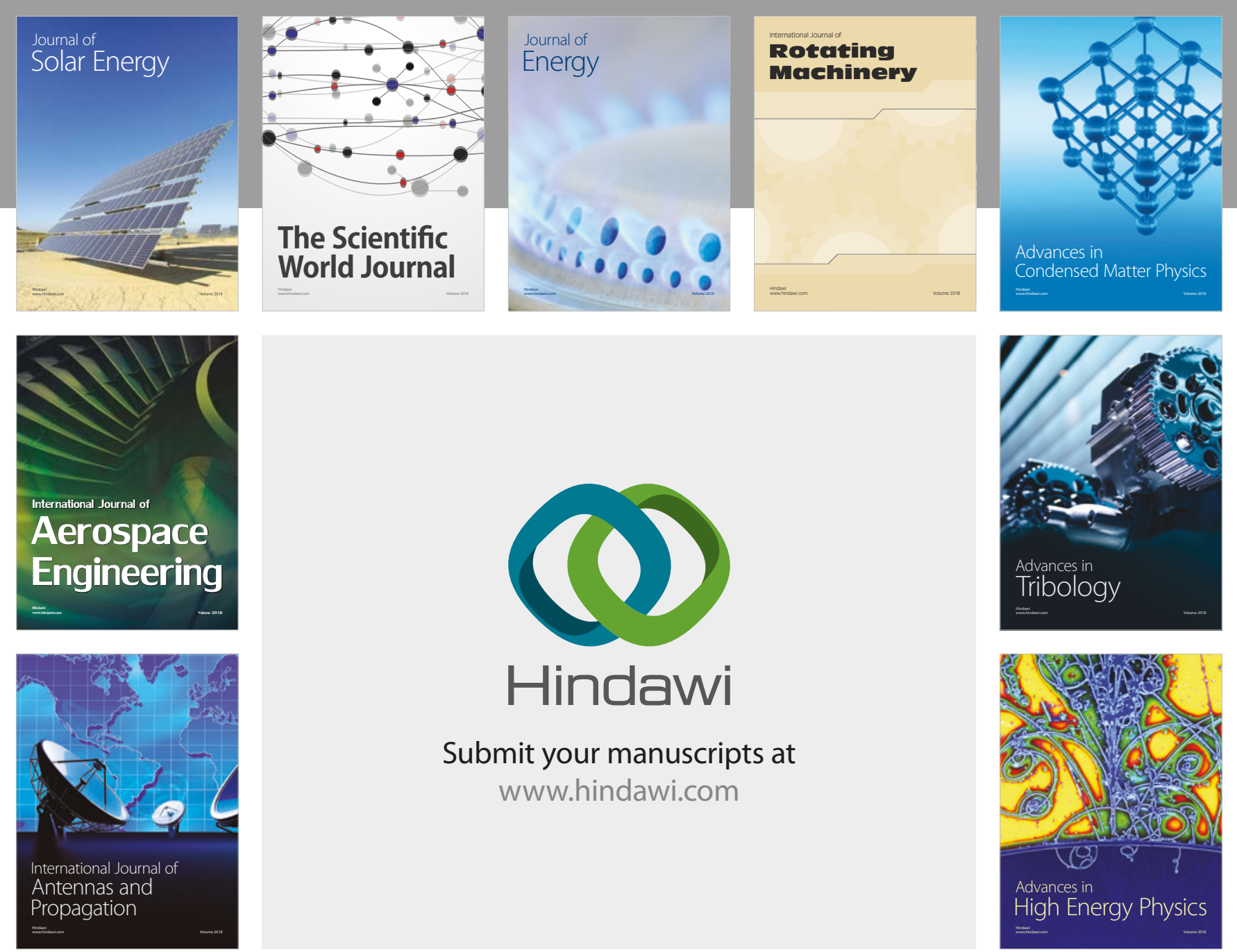

Submit your manuscripts at

www.hindawi.com
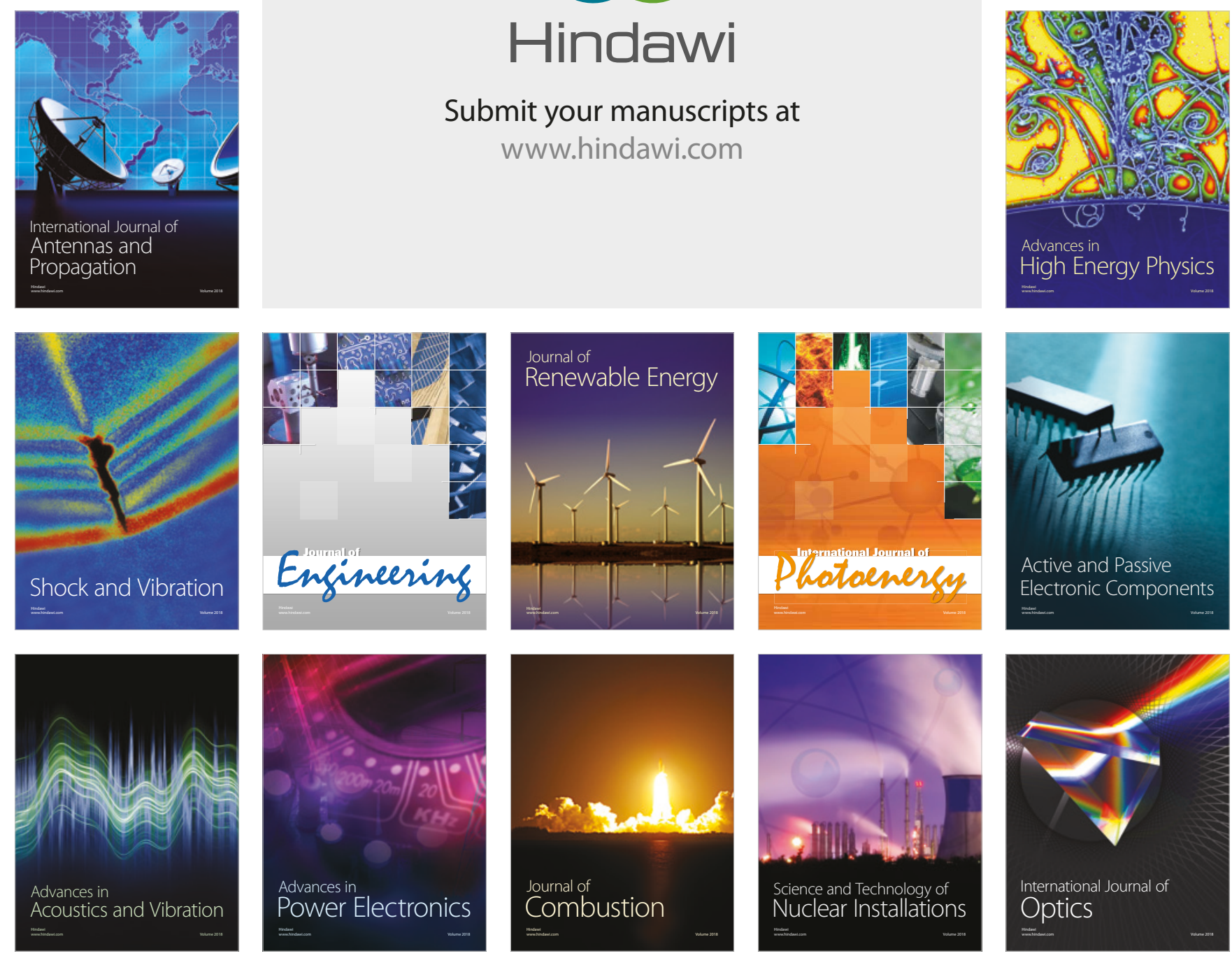